\title{
AsHSP26.8a, a creeping bentgrass small heat shock protein integrates different signaling pathways to modulate plant abiotic stress response
}

\section{Xinbo Sun}

Clemson University

Junfei Zhu

Hebei Agricultural University

Xin Li

Hebei Agricultural University

Zhigang Li

Clemson University

Liebao Han

Beijing Forestry University

Hong Luo ( $\nabla$ hluo@clemson.edu )

Clemson University https://orcid.org/0000-0001-9223-1786

Research article

Keywords: creeping bentgrass, AsHSP26.8a, ABA,abiotic stress, small heat shock protein

Posted Date: March 18th, 2020

DOI: https://doi.org/10.21203/rs.2.16642/v2

License: (9) (i) This work is licensed under a Creative Commons Attribution 4.0 International License.

Read Full License

Version of Record: A version of this preprint was published at BMC Plant Biology on April 28th, 2020. See the published version at https://doi.org/10.1186/s12870-020-02369-5. 


\section{Abstract}

Background: Small heat shock proteins (SHSPs) are critical for plant response to biotic and abiotic stresses, especially heat stress. They have also been implicated in various aspects of plant development. However, the acting mechanisms of the sHSPs in plants, especially in perennial grass species, remain largely elusive.

Results: In this study, AsHSP26.8a, a novel chloroplast-localized sHSP gene from creeping bentgrass (Agrostis stolonifera L.) was cloned and its role in plant response to environmental stress was studied. AsHSP26.8a encodes a protein of $26.8 \mathrm{kDa}$. Its expression was strongly induced in both leaf and root tissues by heat stress. Transgenic Arabidopsis plants overexpressing AsHSP26.8a displayed reduced tolerance to heat stress. Furthermore, overexpression of AsHSP26.8a resulted in hypersensitivity to hormone ABA and salinity stress. Global gene expression analysis revealed AsHSP26.8a-modulated expression of heat-shock transcription factor gene, and the involvement of AsHSP26.8a in ABAdependent and -independent as well as other stress signaling pathways.

Conclusions: Our results suggest that AsHSP26.8a may negatively regulate plant response to various abiotic stresses through modulating $A B A$ and other stress signaling pathways.

\section{Background}

The heat shock proteins (HSPs) are virtually ubiquitous molecules in plants that are rapidly induced by heat stress [1, 2]. At least six types of HSPs, HSP100 (Clp), HSP90, HSP70 (DnaK), HSP60, HSP40 (DNAJ) and small HSPs (sHSPs) have been identified in higher plants, of which the sHSPs with a molecular mass of 12 to $42 \mathrm{kDa}$ are found ubiquitously in all kingdoms of life [3]. The sHSPs function as molecular chaperones, both in vitro and in vivo, to protect cells from stress damage by preventing irreversible protein aggregation and maintaining denatured proteins in a folding-competent state [2, 4-8]. Based on sequence homology, immunological cross-reactivity and subcellular localization, the sHSPs can be further classified into different groups. A total of 12 subfamilies of sHSPs have been identified in various plant species, such as maize (Zea mays L.), Kashgar tamarisk (Tamarix hispida), creeping bentgrass (Agrostisc stolonifera L.), poplars (Populus), Pearl millet (Pennisetum glaucum L.), tall fescue (Festuca arundinacea Schreb.) [9-15]. They are localized in different places within the cell including cytosol or nucleus, mitochondria, plastids (P), endoplasmic reticulum (ER) and peroxisomes (Po) [15-17]. Most of the sHSP subfamily proteins are structurally similar with a highly variable $\mathrm{N}$-terminal region, a conserved core domain of about 100 amino acids and a short C-terminal region $[2,18]$.

Apart from heat stress, sHSPs are induced in response to a number of other environmental adversities such as osmotic stress (e.g. salt, drought), oxidative stress, cold stress, heavy metal stress and phytohormone $A B A[6,11,15,16,19]$, suggesting its involvement in plant response to general abiotic stresses. Additionally, their implication in various aspects of plant development have also been documented [16, 20-22]. 
The roles different sHSPs play in positively regulating plant responses to heat and other environmental stresses (drought, $\mathrm{NaCl}$, mannitol and $\mathrm{H}_{2} \mathrm{O}_{2}$ ) have largely been reported in various plant species and most of them belong to cytosolic sHSPs [10, 21, 23-32]. Class I and II sHSPs have mainly contributed to the current model for sHSP chaperone activity. These two classes of sHSPs have both unique and overlapping functions and act in conjunction with HSP101 to either directly or indirectly protect specific translation factors in cytosolic stress granules [33]. Extensive evolutionary analysis indicates that organelle-targeted sHSPs (chloroplast, mitochondria, peroxisomes, and endoplasmic reticulum) are closely related to their class I counterparts [34-36]. Endoplasmic reticulum-located sHSP, sHSP22, together with $A B A$ insensitive 1 ( $A B \mid 1)$ protein phosphatase controls polar auxin transport and orchestrates ABA and auxin signaling crosstalk in Arabidopsis [37]. Peroxisome-located sHSPs activate catalase to regulate plant abiotic stress resistance [38]. A mitochondrial matrix-localized small heat shock protein in cotton, GhHSP24.7, positively controls seed germination via temperature-dependent ROS generation [39]. Overexpression of the chloroplast sHSP has been associated with cold, heat and oxidative stress tolerance [21, 26]. A typical chloroplast-localized sHSP, HSP21, has been identified in many plant species. Several studies have suggested that HSP21 protects the thermolabile photosystem II (PSII) against heat stress [9, 26, 40-42] and oxidative stress [26, 43]. HSP21 is activated by the GUN5mediated retrograde signaling pathway and stabilizes PSII by directly binding to its subunits under heat stress [44]. HSP21 also interacts with plastid nucleoid protein pTAC5 and is essential for chloroplast development under heat stress by maintaining plastid-encoded RNA polymerase (PEP)-dependent transcription [22]. In addition, HSP21 is involved in extended thermomemory in Arabidopsis. Abundant HSP21 during the memory stage is negatively regulated by heat-induced plastid-localized metalloprotease FtsH6 [45]. Our recent study characterizing sHSPs in perennial grasses identified three creeping bentgrass sHSPs, AsHSP17 (previously named ApHSP16.5) (KT272405), AsHSP26.7 (previously named ApHSP26.7) (AY153761) and AsHSP26.8 (previously named ApHSP26.8) (AY153760) [9, 46-48]. AsHSP17 and AsHSP26.8 genes were significantly induced in transgenic creeping bentgrass overexpressing a rice SUMO E3 ligase gene, OSSIZ1 and exhibiting improved heat tolerance compared to wild type controls [46]. In transgenic creeping bentgrass ectopically expressing a cyanobacterial flavodoxin and exhibiting enhanced heat stress tolerance, AsHSP17, AsHSP26.7 and AsHSP26.8 were all significantly induced but differentially regulated in wild type (WT) and transgenic (TG) plants [47]. Additionally, overexpression of a rice miroRNA, OsmiR393 improves heat tolerance in transgenic creeping bentgrass that is associated with enhanced expression of sHSP genes, AsHSP17 and AsHSP26.7 [48]. Further analysis of AsHSP17, one of these turfgrass SHSPs revealed that AsHSP17 is a negative regulator attenuating plant response to abiotic stress through modulating plant photosynthesis and ABAdependent and independent signaling [15].

To better understand how sHSPs function in perennial grasses to regulate plant stress response, we focused on AsHSP26.8, initially obtained from A. stolonifera cv Penncross as ApHSP26.8 [9], and cloned its ortholog gene, AsHSP26.8a from A. stolonifera cv Penn-A4 encoding a chloroplast-localized creeping bentgrass SHSP. The cloned AsHSP26.8a was introduced into Arabidopsis plants for characterization. Transgenic analysis revealed that constitutive expression of AsHSP26.8a led to significantly increased 
plant susceptibility to several abiotic stresses including heat and salt as well as treatment with hormone ABA. Our results suggested that similar to AsHSP17, AsHSP26.8a may also function as a protein chaperone to negatively regulate plant stress response.

\section{Results}

\section{Cloning and sequence analysis of AsHSP26.8a and its protein subcellular localization}

In our previous study manipulating sumoylation process in transgenic plants for enhanced tolerance to environmental adversities, it was revealed that overexpression of OsSIZ1, a rice E3 SUMO ligase in transgenic creeping bentgrass enhances plant tolerance to a number of abiotic stresses including heat stress associated with altered expression of two sHSP genes, AsHSP17 and AsHSP26.8 [46]. Further investigation of AsHSP17 uncovered its role in modulating plant photosynthesis and ABA-dependent and independent signaling to attenuate plant response to abiotic stress including heat and salt stress [15]. We were also curious about how AsHSP26.8 contributes to OsSIZ1-mediated plant stress response and therefore cloned its ortholog gene from the heat-stressed plants of creeping bentgrass cultivar, Penn A-4 and designated it as AsHSP26.8a. The AsHSP26.8a gene is $729 \mathrm{bp}$ long encoding a protein of 242 amino acids. The predicted polypeptide has a molecular weight (MW) of $26.78 \mathrm{kD}$ and an isoelectric point (pl) of approximately 6.03. Differences in nine nucleotides were identified between AsHSP26.8a and ApHSP26.8 DNA sequences, which led to changes in three amino acids (Fig. S1). Sequence alignment of AsHSP26.8a and the representative plant SHSPs allowed identification of a chloroplast transit peptide (I), a Met-rich region (II) and two consensus regions (III and IV) in AsHSP26.8a (Fig. S2), which was phylogenetically classified as a chloroplast-localized sHSP (Fig. S3).

To further confirm its subcellular localization in the chloroplasts, AsHSP26.8a-green fluorescent protein (GFP) fusion gene was introduced into rice (Oryza sativa) protoplasts. The GFP fluorescence was found to be localized to the nucleoids inside chloroplasts, which is mostly associated with thylakoids (Fig. 1), similar to that of the AtHSP21 (AT4G27670), a well-characterized homolog sHSP of AsHSP26.8a in Arabidopsis thaliana [22]. This result indicates that AsHSP26.8a is specifically localized to the thylakoids membranes within chloroplasts.

\section{AsHSP26.8a expression in response to heat stress}

Our previous study showed that AsHSP26.8 is strongly induced by heat stress in creeping bentgrass leaf [46]. To investigate whether the AsHSP26.8a responds to heat and other abiotic stresses and ABA stimulus, we examined the expression pattern of the AsHSP26.8a in creeping bentgrass under heat, salinity and drought stress as well as exogenous ABA treatment. Total RNAs extracted from leaves and roots were subjected to semi-quantitative RT-PCR analysis. As shown in Fig. 2, the expression of AsHSP26.8a in leaves and roots was strongly induced by heat stress, confirming our previous observation 
[46]. However, no expression was detected in creeping bentgrass leaves or roots subjected to salinity and drought stress as well as ABA treatment (Fig. 2). It should be noted that the very low basal expression level of AsHSP26.8a may prevent its detection even if it does respond to salinity, drought and ABA. With the high sequence similarity between AsHSP26.8a and other sHSPs such as AsHSP26.2 (AY153578), AsHSP26.7 and AsHSP26.8, we were unable to perform quantitative-real-time reverse transcription PCR (qRT-PCR) analysis for AsHSP26.8a expression because of the difficulty in designing appropriate PCR primers.

\section{Generation of transgenic $A$. thaliana plants constitutively expressing AsHSP26.8a}

To further investigate the role of AsHSP26.8a in plant response to abiotic stress, we set to manipulate AsHSP26.8a expression in transgenic plants. To this end, an ASHSP26.8a overexpression vector was constructed (Fig. $3 \mathrm{~A}$ ) for transformation into $A$. thaliana ecotype Columbia. The six independent transgenic lines generated (Fig. 3B, C) did not appear different from wild type controls, of which four homozygous lines, TG1, TG2, TG3 and TG6 expressing different levels of AsHSP26.8a (Fig. 3B, C) were further analyzed. It should be noted that in this study, we chose to use wild type plants as the control in characterizing AsHSP26.8a transgenic plants based on the observation that their development and response to various stresses exhibited no significant difference from that of the transgenic lines harboring an empty vector or a gus reporter gene (data not shown).

\section{AsHSP26.8a overexpression leads to increased heat susceptibility in transgenic plants}

To evaluate how altered AsHSP26.8a expression impacts plant response to high temperature, we subject the well-developed 3 weeks old AsHSP26.8a-overexpressing transgenic plants to heat stress $\left(40^{\circ} \mathrm{C}\right)$ and evaluated their performance in comparison with non-transgenic plants. As shown in Fig. 4B, two-day heat stress led to non-recoverable severe damage in the majority of the transgenic plants, whereas the heatelicited damage was barely observed in wild type controls, all of which recovered and survived the treatment (Fig. 4C, D). Plant relative water content (RWC) and electrolyte leakage (EL) were measured to exam their water status and cell membrane integrity. While similar RWC and EL were observed in both transgenic and wild type control plants under normal growth conditions, there was a significantly more water loss and a more severe heat-elicited cell membrane damage in the AsHSP26.8a-expressing transgenics than in the control plants two days after heat treatment (Fig. 4E, F), suggesting that AsHSP26.8a negatively impacts plant water retention capacity and cell membrane integrity. Similarly, although no significant difference in chlorophyll a, b and total chlorophyll contents was observed between wild type control and the AsHSP26.8a-containing plants under normal growth conditions, the AsHSP26.8a-expressing transgenic plants exhibited significantly lower leaf chlorophyll a, b and total chlorophyll contents than wild type control under heat-stress conditions (Fig. 4G) suggesting a reduced 
chlorophyll production in AsHSP26.8a transgenic plants under heat stress. It should be noted that the inconsistent phenotypes of the TG1 plants in the three pots used for heat stress response assessment (Fig. 4A-D) was most likely due to random experimental errors rather than the inherent difference between individual transgenic plants.

\section{AsHSP26.8a transgenic plants exhibit increased salinity susceptibility}

To investigate possible involvement of AsHSP26.8a in plant response to other abiotic stresses, we examined seed germination of AsHSP26.8a overexpressing plants subjected to salt stress (Fig. 5) and observed that transgenic plants exhibited significantly lower seed germination than the wild type controls when treated with 125 or $150 \mathrm{mM} \mathrm{NaCl}$, under which the germination rate was only approximately $60-80 \%$ in the AsHSP26.8a transgenics versus $100 \%$ in wild type controls (Fig. 5A, B). Similarly, plant postgermination growth in AsHSP26.8a-expressing transgenic plants was also significantly impaired compared to wild type controls under the two different $\mathrm{NaCl}$ concentrations (Fig. 5A, C). These data indicate that besides heat stress, AsHSP26.8a also impacts how plants tackle other environmental adversities. More specifically, it negatively regulates plant salinity stress response.

\section{AsHSP26.8a overexpression impacts ABA signaling in transgenic plants}

Among various phytohormones, $\mathrm{ABA}$ is the central regulator of abiotic stress resistance in plants and coordinates an array of functions [56-58]. We were curious about the possible involvement of AsHSP26.8a in plant ABA signaling. To this end, we conducted experiments assessing plant response to exogenous $\mathrm{ABA}$ treatment $(0,0.75$ and $1 \mu \mathrm{M})$ and found that compared to wild type controls, seed germination and post germinative plant growth in AsHSP26.8a transgenics were both significantly reduced responding to ABA application (Fig. 6), suggesting that AsHSP26.8a may function as a positive regulator mediating $\mathrm{ABA}$-associated plant development.

\section{Genome-wide gene expression analysis in AsHSP26.8a overexpression transgenic plants}

To better understand molecular mechanisms underlying AsHSP26.8a involvement in plant abiotic stress response, we conducted genome-wide gene expression analysis in wild type and AsHSP26.8a transgenic plants to screen for differentially expressed genes (DEGs) between the two genotypes (Table S1). Among a total of 269 DEGs identified, 20 (7\%) were up-regulated and 249 (93\%) down-regulated. Absolute log2 fold changes ranged from -6.80 to 4.84 and adjusted P-value (FDR) ranged from $1.61 \times 10^{-77}$ to $0.99 \times 10^{-2}$. Allocated gene ontology (GO) term-based classification of the 269 DEGs resulted in 53 different groups. 
One of the most dominant GO terms was 'Response to stimulus' in the biological process category (Fig. S4). Additionally, many genes responsive to phytohormones (ABA, ethylene, jasmonic acid, auxin, salicylic acid, gibberellin) and abiotic stresses (drought, cold, salinity, oxidative stress, cadmium ion and heat) as well as those involved in various stress-related signaling pathways (salicylic acid mediated signaling pathway, jasmonic acid mediated signaling pathway, abscisic acid-activated signaling pathway, ethylene-activated signaling pathway) were also identified (Fig. 7).

A total of 88 abiotic stress-related DEGs identified from the RNA-seq data were all functionally annotated that encode either regulatory or functional proteins (Table 1). The regulatory proteins consist of 30 transcription factors (e.g. AP2/ERF, DREB, HSF, MYB, NAC, WRKY and Zinc finger protein), 10 signaling proteins (e.g. calcium-binding proteins) and 17 kinases (e.g. cysteine-rich receptor-like protein kinase, leucine-rich repeat protein kinase, mitogen-activated protein kinase kinase kinase 14, S-locus lectin protein kinase family protein and wall-associated receptor kinase-like 2). The functional proteins include six cytochrome P450 family members, three LEA proteins, four carbohydrate metabolism-related proteins, thirteen nitrogen metabolism-related proteins, four proteins involved in oxidation-reduction process and one AAA-type ATPase family protein. The majority of these 88 abiotic stress-related DEGs were downregulated except six encoding one MYB domain protein, one protein kinase, one cytochrome P450 family member, one alpha/beta-hydrolase family protein and two proteins involved in oxidation-reduction process). The differential expression patterns of the four representative abiotic stress responsive genes, DREB1B, ERF105, HSFB2a and HSFC1 between wild type control and the AsHSP26.8a transgenic plants were confirmed by qRT-PCR analysis (Table 2), further validating the RNA-seq data.

\section{Discussion}

The sHSPs, especially those in plants, are a large and complex family of proteins [35]. The plant sHSPs are divided into 12 subfamilies, of which chloroplast-localized sHSPs family has been identified in diverse higher plant species $[59,60]$. This family of sHSPs have a Met-rich domain and a unique amphipathic domain at their N-terminus, not present in other sHSPs. AsHSP26.8a possesses both a Metrich domain and a chloroplast transit peptide at its N-terminus (Fig. S2). Phylogenetic analysis and subcellular localization further support the classification of the AsHSP26.8a protein as a member of the chloroplast-localized sHSPs family (Fig.S3 and Fig. 1).

\section{AsHSP26.8a-mediated HSP/HSF pathway and plant abiotic stress tolerance}

The major abiotic stresses such as drought, high salinity, extreme temperature, negatively influence plant survival, growth and productivity. As sessile organisms, plants are unable to change their sites to escape from the unfavorable environmental adversities but have developed a great degree of resilience to conditions that would be considered harmful to many other organisms. A network of interconnected cellular stress response systems is essential for plant survival and productivity [61]. Within the complex stress response network, transcription factors (TFs) play a core role in the conversion of stress signal perception to stress-responsive gene expression by interacting with the promoter regions of various target 
stress-responsive genes, thus activating the whole network of genes to act together in enhancing plant tolerance to the harsh environmental conditions [62]. Heat shock transcription factors (HSFs) are the central regulators in plant cellular response to various abiotic stresses, especially to heat stress $[63,64]$. Class B HSF and Class C HSF have been implicated in plant response to heat stress. HSFB1 and HSFB2b repress the expression of HSFs, but positively impact the acquired thermotolerance [65]. Capsicum annuum HSFB2a forms a transcriptional cascade with CaWRKY 6 and CaWRKY 40 to positively regulate the response to high temperature and high humidity [66]. Guan et al. [67] found that regulation of heat stress-responsive genes including HSFC1 and other HSFs by RCF2 and its interacting partner NAC transcription factor NAC019 is critical for thermotolerance in Arabidopsis. A recent study showed that HSFC1b from tall fescue plays a positive role in plant tolerance to heat stress in association with the induction and upregulation of heat-protective genes [68]. Our results showed that overexpression of AsHSP26.8a alters plant heat stress response (Fig. 4) and results in down-regulated expression of the two HSFs, HSFB2a and HSFC1 in transgenic plants (Table 1), suggesting that AsHSP26.8a may function to repress HSF gene expression, modulating heat-responsive genes and thus attenuating plant response to heat stress.

\section{AsHSP26.8a modulates ABA-dependent stress signaling and plant abiotic stress response}

ABA, commonly known as the "stress hormone", responds to an array of biotic and abiotic stresses [69]. Under osmotic stress condition such as drought and high salinity stress, a number of genes functioning in stress response and tolerance are induced, and ABA is accumulated [56, 70, 71]. The expression of stress-responsive genes is regulated by ABA-dependent and ABA-independent pathways [71]. These genes encode the late embryogenesis abundant (LEA) proteins, enzymes, transcription factors, protein kinases et al. LEA accumulation is a functional adaptation of plants in gaining tolerance against osmotic as well as oxidative stresses [72]. Overexpression of genes encoding LEA proteins can improve the stress tolerance of transgenic plants [73-76]. MYB transcription factors are a large group of proteins identified in eukaryotes and widely distributed in plants [77-79]. Some of the MYB protein family members are involved in ABA-dependent signaling pathways regulating stress adaption and conferring plant stress tolerance [78, 80-82]. In this study, overexpression of AsHSP26.8a alters plant development and plant response to $A B A$ and salt stress (Fig. 5 and 6) and leads to significantly reduced expression of several genes encoding LEA and MYB proteins (Table 1) as well as some stress-responsive transcription factors, such as WRKY transcription factors, involved in ABA-dependent signaling [83]. Abiotic stresses such as heat, high salinity and drought also induce the WRKY genes and trigger a cascade of signaling pathways for improved plant stress tolerance $[84,85]$. Many studies showed that overexpression of a WRKY family gene confers abiotic stress tolerance in transgenic plants. For example, AtWRKY25 and AtWRKY26 overexpression enhanced plant heat tolerance in transgenic Arabidopsis [86]. Transgenic Arabidopsis overexpressing a wheat WRKY transcription factor, TaWRKY33 exhibited enhanced heat tolerance [87]. In cotton, GhWRKY17 overexpression increased plant sensitivity to drought and salt stress as well as ABAmediated seed germination and root growth by reducing the levels of $A B A$ and transcripts of ABAinducible genes including NbAREB1 (ABA-responsive element binding), NbDREB (dehydration-responsive element binding), NbNCED (9-cis-epoxycarotenoid dioxygenase), NbERD (early responsive to dehydration) 
and LEA protein, NbLEA [88]. These data suggest that AsHSP26.8a may function as a chaperone protein, contributing to ABA-dependent signaling in plant abiotic stress responses.

\section{AsHSP26.8a modulates ABA-independent stress signaling and plant abiotic stress response}

Our results also showed that AsHSP26.8a modulates stress-related transcription factor gene expression in the ABA-independent signaling pathways. The ABA-independent stress-responsive gene expression is regulated by DREB proteins. DREBs belong to Ethylene Response Factor (ERF)/AP2 family and consist of two subclasses, DREB1/CBF and DREB2 induced by cold and dehydration/high salinity, respectively [71, 89-96]. Arabidopsis DREB1A overexpression was reported to enhance LEA protein levels and therefore abiotic stress tolerance in Arabidopsis $[97,98]$ and various crops including rice, soybean, peanut and wheat [99-102]. Heterologous expression of AtDREB1B in Salvia miltiorrhiza enhanced plant drought tolerance by activating different downstream DREB/CBF genes [103]. Moreover, AtHSFA3 is a transcription factor that is transcriptionally induced during heat stress by DREB2A and in turn regulates the expression of HSP-encoding genes [104]. Overexpressing AtDREB2A in Arabidopsis plants induces not only drought- and salt-responsive genes but also heat-shock-related genes. Thermotolerance was significantly increased in plants overexpressing DREB2A and decreased in DREB2A knockout plants [92]. The ERF (ethylene-responsive element binding factor) is another subfamily of the AP2/ERF family of TFs and plays vital roles in the regulation of biotic and abiotic stress responses [105-107]. Overexpression of a tomato ERF transcription factor, SIERF84 in Arabidopsis endows transgenic plants with ABA hypersensitivity and enhanced tolerance to drought and salt stress [108]. Overexpression of CmERF053 of chrysanthemum could enhance drought tolerance [109]. In Tamarix hispida, constitutive expression of an ERF transcription factor, ThCRF1, increased biosynthesis of trehalose and proline and the activities of SOD and POD, resulting in an altered osmotic potential and an enhanced reactive oxygen species (ROS) scavenging, and therefore significantly improved salt tolerance in transgenic plants. On the contrary, suppression of ThCRF1 led to decreased plant salt tolerance [110]. In this study, transgenic plants overexpressing AsHSP26.8a displayed significant expression changes in ten ERF/AP2 family genes (Table 1), for example, compared to the wild type, DREB1B/CBF1 and ERF105 expression in AsHSP26.8a transgenic plants was down-regulated over sixty-fold and thirty-fold, respectively (Table 1). These results suggest that AsHSP26.8a-modulated expression of the genes in the ABA-independent signaling pathways may also contribute to plant response to various abiotic stresses.

\section{Other stress signaling pathways mediated by AsHSP26.8a and plant abiotic stress response}

Calcium $\left(\mathrm{Ca}^{2+}\right)$ is the most widely accepted second massager and involved in plant stress responses and cytoplasmic $\mathrm{Ca}^{2+}$ signal is recognized by $\mathrm{Ca}^{2+}$ sensors including calmodulins (CaM), calmodulin-like proteins (CMLs), calcium dependent protein kinases (CDPKs) and calcineurin B-like proteins (CBLs) [111118]. Overexpression of AtCML24 enhances transgenic Arabidopsis tolerance to various ions including $\mathrm{Co}^{2+}, \mathrm{Zn}^{2+}$ and $\mathrm{Mg}^{2+}[119]$. CML18 directly interacts with $\mathrm{Na}^{+} / \mathrm{H}^{+}$antiporter $\mathrm{NHX} 1$ to regulate plant salinity tolerance [120]. CML9 is suggested to negatively regulate ABA-dependent salinity tolerance [121]. OsANN1, a calcium-binding protein of rice modulates antioxidant accumulation under abiotic stress to 
confer abiotic stress tolerance. OsANN1-knockdown led to increased plant sensitivity to heat and drought stresses, whereas OsANN1 overexpression resulted in improved plant growth with higher expression of OsANN1 under abiotic stress [122]. Receptor-like protein kinases (RLKs), a class of single-pass transmembrane proteins located in the plasma membrane, sense and transmit a variety of signals to regulate plant growth and development $[123,124]$. Many RLKs have been implicated in abiotic stress responses, including the abscisic acid response, calcium signaling and antioxidant defense. Upon drought stress, the Arabidopsis LRK10L1.2 responds to directly or indirectly regulate stomata closure via ABA-mediated signaling [125], while a Glycine soja ABA-responsive receptor-like cytoplasmic kinase (RLCK), GsRLCK, responds to modulate ABA sensitivity in plants by regulating the expression of ABAresponsive genes [126]. In Pisum sativum, salinity induced lectin receptor-like kinase (PsLecRLK) gene expression and overexpression of PsLecRLKs led to improved plants salt tolerance due to enhanced ROSscavenging [127]. In Medicago spp., the LRR-RLK gene, SRLK has been shown to regulate the root response to salt stress [128]. Large families of zinc finger transcription factors are abundant in plants and have diverse functions including DNA binding and transcriptional regulation [129]. Cys2/His2-type $(\mathrm{C} 2 \mathrm{H} 2)$ zinc finger proteins are implicated in plant response to a variety of adversities including lowtemperatures, salt, drought, oxidative stress, excessive light and silique shattering [130-132]. One example is ZAT6 in Arabidopsis that positively regulates cadmium tolerance via the glutathione-dependent pathway [133]. Another example is the $\mathrm{C} 2 \mathrm{H} 2$ zinc finger protein gene, Zat7 whose constitutive expression suppressed growth and enhanced salt tolerance in transgenic Arabidopsis plants [134]. Moreover, transgenic analysis in Arabidopsis points to the involvement of ZAT10 or STZ (salt tolerance zinc finger) in determining plant tolerance to drought, salt, osmotic, heat, photo-inhibitory light and oxidative stresses [135-138]. In this study, AsHSP26.8a overexpression led to significantly reduced expression of the genes encoding four CMLs, fifteen RLKs and nine zinc finger proteins in transgenic Arabidopsis (Table 1). For example, ZAT11 expression in AsHSP26.8a TG Arabidopsis plants was down-regulated over thirty-fold and ZAT12, ZAT7, CML 38 and $C M L 30$ were down-regulated over sixteen-fold compared to wild type controls (Table 1). These results suggest that other than the ABA-dependent and -independent signaling pathways, AsHSP26.8a may also participate in other signaling pathways responding to abiotic stresses.

A few studies about the negative effect of HSPs on plant response to abiotic stress have previously been reported. Song et al. [139] found that transgenic Arabidopsis overexpressing cytosolic and organellar AtHSP90s exhibited suppressed expression of stress-responsive genes and consequently reduced salt and drought tolerance. Our previous study also showed that overexpression of AsHSP17, a creeping bentgrass SHSP, attenuates plant response to abiotic stress by modulating plant photosynthesis and ABA-dependent and -independent signaling [15]. Moreover, Wang and Luthe [9] were unable to amplify ApHSP26.8 (renamed as AsHSP26.8 in this study) from the heat-tolerant variant selected bentgrass, which was regenerated from callus that survived selection at $40^{\circ} \mathrm{C}$ for 1 week, but they were able to amplify the gene from the heat-sensitive variant non-selected bentgrass, which was not subjected to heat stress. Taken together, these data imply that similar to AsHSP17, as a chaperone protein, AsHSP26.8a may be regulated to maintain an appropriate level in protecting a stressed plant. The excessive amount of AsHSP26.8a in transgenic plants may negatively impact the stress response regulatory network, 
compromising on plant stress tolerance. Indeed, our results assessing plant performance under stressful conditions showed that the plant response to heat stress in different transgenic lines appeared quite consistent regardless of the level of the elevated AsHSP26.8a expression (Fig. 3C and Fig. 4B-D). It is therefore tempting to speculate that any change in AsHSP26.8a expression above the basal level would have significant impact on plant response to environmental stress. Alternatively, AsHSP26.8a may need to stay inactive under normal condition not to become a stress itself. Using transgenic approach, we are currently investigating the impact of the regulated expression of AsHSP26.8a in creeping bentgrass itself in order to better understand molecular mechanisms of AsHSP26.8a-mediated plant development and stress response.

\section{Conclusions}

We have cloned and characterized a chloroplast localized sHSP gene, AsHSP26.8a, whose expression is induced by heat stress. Overexpression of $A s H S P 26.8 a$ in transgenics attenuates plant response to various abiotic stresses including heat, salt and ABA. AsHSP26.8a may be involved in several aspects of plant stress response including ABA-dependent and -independent signaling and some other stress response pathways. Although the molecular mechanisms of the possible chaperone role AsHSP26.8a may play in plant stress response remain to be unraveled, the results obtained from the current study allow a better understanding of sHSPs involvement in plant abiotic stress response providing information for prospecting studies towards the development of novel molecular strategies for enhancing crop performance under adverse environments.

\section{Methods}

\section{Plant materials and abiotic stress treatment}

The creeping bentgrass cultivar 'Penn-A4' originally provided by HybriGene (Hubbard, OR) was clonally propagated from stolon and maintained as described previously [49]. Plants were maintained in the growth room and subjected to heat, salt, drought and phytohormone treatment as described previously [15]. The leaf samples were collected at $0,0.5,2$ and $4 \mathrm{~h}$ and roots were collected at 0 and $4 \mathrm{~h}$ after stress treatment for RNA extraction to clone the AsHSP26.8a gene and analyze AsHSP26.8a gene expression.

The wild type $A$. thaliana plants (ecotype Columbia) and four transgenic lines (TG1, TG2, TG3 and TG6) generated by Xinbo Sun were cultured in a growth chamber and subjected to heat stress as described previously [15]. The seeds of the transgenic lines obtained are maintained and available in Hong Luo's lab at Clemson University (Clemson, SC).

\section{Plant genomic DNA, RNA isolation and gene expression analysis}


Plant genomic DNA was extracted as described previously [50]. Plant total RNA was extracted from 100 mg of fresh leaves/roots with Trizol reagent (Invitrogen, Carlsbad, CA) following the manufacturers' protocol. First-stand cDNA was synthesized from $2 \mu \mathrm{g}$ RNA with SuperScript III System (Invitrogen) and oligo (dT) or gene specific primers.

Semi-quantitative RT-PCR was conducted on 25-30 cycles based on its exponential phase. PCR products were analyzed by electrophoresis using a $0.8 \%$ or $1.5 \%(\mathrm{w} / \mathrm{v})$ agarose gel and photographed with the BioDoc-lt imaging system (Ultra -Violet Products). The creeping bentgrass ubiquitin gene, $A s U B Q$ (JX570760) and A. thaliana Actin1 (AT2G37620) were used as reference genes.

Using the Bio-Rad iQ5 real-time detection system with $12.5 \mu \mathrm{L}$ of iQ SYBR Green Supermix (Bio-Rad Laboratories, Hercules, $C A$ ), quantitative real-time PCR was conducted to verify the expression of four representative DEGs (DREB1B, ERF105, HSFB2a and HSFC1) in WT and TG Arabidopsis plants identified by RNA-seq analysis. The reaction mix was preincubated at $95^{\circ} \mathrm{C}$ for $3 \mathrm{~min}$ followed by 40 cycles of denaturing at $95^{\circ} \mathrm{C}$ for $30 \mathrm{~s}$, annealing at $60^{\circ} \mathrm{C}$ for $30 \mathrm{~s}$, extension at $72^{\circ} \mathrm{C}$ for $20 \mathrm{~s}$. The data were collected by using iQ5 Optical System Software version 2.0 (Bio-Rad Laboratories) with AtActin 1 and AtTub6 (AT5G12250), the two reference genes as endogenous controls for $A$. thaliana analysis. The $\Delta \Delta C t$ method was used for real-time PCR analysis with three biological replicates [49].

\section{Subcellular localization of GFP protein in rice protoplasts}

For subcellular localization, the full-length of AsHSP26.8a without a stop codon was subcloned into the pUC19/35S-EGFP vector with GFP at $C$ terminus. The resulting fusion construct and empty vector were transformed into rice protoplasts by PEG (polyethylene glycol)-mediated transformation method, respectively [51]. After incubation in the dark for 16h, the GFP fluorescence of transiently transformed rice protoplasts was examined and photographed under a confocal scanning microscopy (LSM510 Meta; Zeiss). For GFP, we used 488 and $519 \mathrm{~nm}$ for excitation and emission, respectively. For chlorophyll autofluorescence, we used 488 and 650-750 nm for excitation and emission, respectively.

\section{Plasmid construction and plant transformation}

The AsHSP26.8a overexpression construct, p35S-AsHSP26.8a/35S-bar contains the open reading frame of the turfgrass sHSP gene, AsHSP26.8a, driven by the cauliflower mosaic virus 35S (CaMV35S) promoter and linked to a CaMV35S-driven bar gene for herbicide resistance. The construct was introduced into wild type $A$. thaliana (Col-0) by Agrobaterium tumefaciens (LBA4404)-mediated plant transformation using floral dip. Individual transgenic plants were selected by herbicide screening.

\section{RNA-seq analysis}


The 4-week-old wild type and AsHSP26.8a TG3 seedlings were harvested for total RNA isolation with Trizol reagent (Invitrogen, Carlsbad, CA). RNA concentration, purity and integrity were monitored by Nanodrop, Qubit 2.0 and Agilent 2100 Bioanalyzer. The mRNAs were isolated using oligo (dT) magnetic beads and randomly broken into 150 - to 250 - pieces in fragmentation reagent. The first strand cDNA was generated by employing random hexamer-primers and reverse transcriptase, followed by the synthesis of the second-strand cDNA in the presence of dNTPs, RNase $\mathrm{H}$ and DNA polymerase I. The purified cDNA products after end-reparation, adaptor ligation and size selection by AMPure XP beads were PCRamplified and then sequenced on an Illumina HiSeq2500 (Biomaker Technologies, Beijing, China). The clean reads obtained after removal of low-quality reads and adaptor sequences from the raw reads of each library were mapped to the reference Arabidopsis genome (TAIR 10, ftp://ftp.ensemblgenomes.org/pub/ plants/release-25/fasta/arabidopsis_thaliana/) using TopHat2 [52]. The FPKM (fragments per kilobase of transcript per million fragments mapped) values were used to measure Gene expression levels [53]. The FDR (false discovery rate) values of $\leq 0.01$ and the FC (fold change) value of $\geq 2$ (the absolute value of $\log 2$ ratio $\geq 1$ ) were used to determine differentially expressed genes (DEGs) in the four libraries from wild type and AsHSP26.8a TG plants (two libraries from two biological replicates for each sample). Gene Ontology (GO) enrichment analysis was conducted by mapping all the DEGs to GO terms in the GO database (http://www. geneontology.org/) and the unigene number in each term was also determined.

Pearson's correlation coefficients [54] between each pair of the biological replicates in WT and TG samples calculated were both close to 1 (Fig. S5), indicating a high RNA-seq data reliability.

We deposited the raw sequence reads into the National Center for Biotechnology Information (NCBI) Short Read Archive (SRA) repository with the accession numbers SRP065638 and SRA308886.

\section{Seed germination assays}

Seed germination assays under salt stress conditions and ABA treatment were performed as described previously [15]. The numbers of germinated seeds and green seedlings were counted on the fourth day. Each assay was repeated three times.

\section{Leaf electrolyte leakage, chlorophyll, relative water contents and photosynthesis parameters}

Measurements of Leaf electrolyte leakage (EL), chlorophyll and relative water content (RWC) were conducted as described previously $[49,55]$. Each measurement was conducted in three replicates.

\section{Statistical analysis}


The data were analyzed by Microsoft Excel 2010 (Microsoft, USA) and significance of differences between data sets was evaluated by SAS software 9.2 (SAS institute Inc. USA).

\section{Declarations}

\section{Ethics approval and consent to participate}

Not applicable.

\section{Consent for publication}

Not applicable.

\section{Availability of data and materials}

All relevant data are included in this article and its supplementary information files.

\section{Competing interests}

The authors declare that they have no competing interests.

\section{Funding}

This project was supported by the National Science Foundation for Young Scientists of China (31701955), the Natural Science Foundation of Hebei Province (C2018204056), Young Talents Support Program of Hebei Province and in part by the Biotechnology Risk Assessment Grant Program competitive grant no. 2019-33522-30102 from the USDA National Institute of Food and Agriculture and the United States Golf Association, Inc. These funding bodies did not play any roles in the design of the study and collection, analysis, and interpretation of data and in writing the manuscript.

\section{Authors' contribution}

$X S, L H$ and HL conceived and designed the experiments. XS, JZ, XL, and ZL conducted experiments. XS and $\mathrm{HL}$ analyzed the data and wrote the manuscript. All authors read and approved the final manuscript.

\section{Acknowledgements}

We wish to thank Dr. Dayong Li for his help in AsHSP26.8a subcellular localization experiment.

\section{Abbreviations}

CaM: Calmodulins; CaMV35S: Cauliflower Mosaic Virus 35S; CBLs: Calcineurin B-Like Proteins (CBLs); CDPKs: Calcium Dependent Protein Kinases; CMLs: Calmodulin-Like Proteins; DEGs: Differentially Expressed Genes; EL: Electrolyte Leakage; FDR: False Discovery Rate; GFP: Green Florescent Protein; GO: Gene Ontology; HSFs: Heat Shock Transcription Factors; HSPs: Heat Shock Proteins; LEA: Late 
Embryogenesis Abundant; MW: Molecular Weight; RNA-seq: RNA sequencing; RWC: Relative Water Content; TF: Transcription Factor

\section{References}

1. Howarth CJ. Molecular responses of plants to an increased incidence of heat shock. Plant Cell Environ. 1991; 14:831-41.

2. Basha $E, O^{\prime}$ Neill H, Vierling E. Small heat shock proteins and a-crystallins: Dynamic proteins with flexible functions. Trends Biochem Sci. 2012; 37:106-17.

3. Haslbeck M, Franzmann T, Weinfurtner D, Buchner J. Some like it hot: the structure and function of small heat shock proteins. Nat Struct Mol Biol. 2005; 12:842-46.

4. Lee GJ, Roseman AM, Saibil HR Vierling E. A small heat shock protein stably binds heat-denatured model substrates and can maintain a substrate in a folding-competent state. EMBO J. 1997;16: 659-71.

5. Sun W, Bernard C, van de Cotte B, van Montagu M, Verbruggen N. 6A, encoding a small heat-shock protein in Arabidopsis, can enhanceosmotolerance upon overexpression. Plant J. 2001;27: 407-15.

6. Sun Y, MacRae TH. Small heat shock proteins: molecular structure and chaperone function. Cell Mol Life Sci. 2005; 62:2460-76.

7. McHaourab HS, Godar JA, Stewart PL. Structure and mechanism of protein stability sensors: chaperone activity of small heat shock proteins. Biochemistry. 2009; 48:3828-37.

8. Eyles SJ, Gierasch LM Nature's molecular sponges: small heat shock proteins grow into their chaperone roles. Proc Natl Acad Sci USA. 2010; 107:2727-28.

9. Wang $D$, Luthe DS. Heat sensitivity in a bentgrass variant. failure to accumulate a chloroplast heat shock protein isoform implicated in heat tolerance. Plant Physiol. 2003;133: 319-27.

10. Sun L, Liu Y, Kong X, Zhang D, Pan J, Zhou Y et al. 9, a cytosolic class I small heat shock protein in maize (Zea mays), confers heat tolerance in transgenic tobacco. Plant Cell Rep. 2012; 31:1473-84.

11. Yang G, Wang Y, Zhang K, Gao C. Expression analysis of nine small heat shock protein genes from Tamarix hispida in response to different abiotic stresses and abscisic acid treatment. Mol Biol Rep. 2014; 41:1279-89.

12. Zhang J, Liu B, Li J, Zhang L, Wang Y, Zheng H, et al. Hsf and Hsp gene families in Populus: genomewide identification, organization and correlated expression during development and in stress response. BMC Genomics. 2015; 16:181.

13. Hu T, Liu S, Amombo E. Fu J. Stress memory induced rearrangements of HSPtranscription, photosystem II photochemistry and metabolism of tall fescue (Festuca arundinacea) in response to high-temperature stress. Front. Plant Sci. 2015; 6:403.

14. Nitnavare RB, Yeshvekar RK, Sharma KK, Vadez V, Reddy MK, Reddy PS. Molecular cloning, characterization and expression analysis of a heat shock protein 10 (Hsp10) from Pennisetum glaucum (L.), a C4 cereal plant from the semi-arid tropics. Mol Biol Rep. 2016; 43: 861-70. 
15. Sun X, Sun C, Li Z, Hu Q, Han L, Luo H. AsHSP17, a creeping bentgrass small heat shock protein modulates plant photosynthesis and ABA-dependent and independent signalling to attenuate plant response to abiotic stress. Plant Cell Environ. 2016; 39:1320-37.

16. Sun W, Van Montagu M, Verbruggen N. Small heat shock proteins and stress tolerance in plants. Biochim Biophys Acta. 2002; 1577:1-9.

17. Siddique M, Gernhard S, von Koskull-Döring P, Vierling E, Scharf KD. The plant sHSP superfamily: five new members in Arabidopsis thaliana with unexpected properties. Cell Stress Chaperones. 2008; 13:183-97.

18. Kim KK, Kim R, Kim SH. Crystal structure of a small heat-shock protein. Nature. 1998; 394:595-99.

19. Park H, Ko E, Jang E, Park S, Lee J, Ahn Y. Expression of DcHSP17.7, a small heat shock protein gene in carrot (Daucus carota). Hortic Environ Biote. 2013;54: 121-27.

20. Volkov RA, Panchuk II, Schöff F. Small heat shock proteins are differentially regulated during pollen development and following heat stress in tobacco. Plant Mol Biol. 2005; 57:487-502.

21. Chauhan H, Khurana N, Nijhavan A, Khurana JP, Khurana P. The wheat chloroplastic small heat shock protein (sHSP26) is involved in seed maturation and germination and imparts tolerance to heat stress. Plant Cell Environ. 2012; 35:1912-31.

22. Zhong L, Zhou W, Wang H, Ding S, Lu Q, Wen X, et al. Chloroplast small heat shock protein HSP21 interacts with plastid nucleoid protein PTAC5 and is essential for chloroplast development in Arabidopsis under heat stress. Plant Cell. 2013; 25:2925-43.

23. Murakami T, Matsuba S, Funatsuki $H$, Kawaguchi K, Saruyama $H$, Tanida M, Sato Y. Over-expression of a small heat shock protein, sHSP17.7, confers both heat tolerance and UV-B resistance to rice plants. Mol Breed. 2004; 13:165-75.

24. Sato Y, Yokoya S. Enhanced tolerance to drought stress in transgenic rice plants overexpressing a small heat-shock protein, sHSP17.7. Plant Cell Rep. 2008; 27:329-34.

25. Jiang $\mathrm{C}, \mathrm{Xu} J$, Zhang H, Zhang X, Shi J, Li M, Ming F. A cytosolic class I small heat shock protein, RcHSP17.8, of Rosa chinensis confers resistance to a variety of stresses to Escherichia coli, yeast and Arabidopsis thaliana. Plant Cell Environ. 2009; 32:1046-59.

26. Kim KH, Alam I, Kim YG, Sharmin SA, Lee KW, Lee SH, Lee BH. Overexpression of a chloroplastlocalized small heat shock protein OsHSP26 confers enhanced tolerance against oxidative and heat stresses in tall fescue. Biotechnol Lett. 2012;34: 371-77.

27. Kim DH, Xu Z, Hwang I. 8 overexpression in transgenic lettuce gives rise to dehydration and salt stress resistance phynotypes through modulation of ABA-mediated signaling. Plant Cell Rep. 2013; 32:1953-63.

28. Zhou Y, Chen H, Chu P, Li Y, Tan B, Ding Y, et al. 5, a cytosolic class II small heat shock protein gene from Nelumbo nucifera, contributes to seed germination vigor and seedling thermotolerance in transgenic Arabidopsis. Plant Cell Rep. $2012 ; 31:$ 379-89.

29. Ham DJ, Moon JC, Hwang SG, Jang CS. Molecular characterization of two small heat shock protein genes in rice: their expression patterns, localizations, networks, and heterogeneous 
overexpressions. Mol Biol Rep. 2013; 40:6709-20.

30. Mu C, Zhang S, Yu G, Chen N, Li X, Liu H. Overexpression of small heat shock protein LimHSP16.45 in Arabidopsis enhances tolerance to abiotic stresses. PLoS One 2013,.8, e82264.

DOI:10.1371/journal.pone.0082264

31. Merino I, Contreras A, Jing ZP, Gallardo F, Cánovas FM, Gómez L. Plantation forestry under global warming: hybrid poplars with improved thermotolerance provide new insights on the in vivo function of small heat shock protein chaperones. Plant Physiol. 2014;164: 978-91.

32. Santhanagopalan I, Basha E, Ballard KN, Bopp NE, Vierling E. Model chaperones: small heat shock proteins from plants. In RM Tanguay, LE Hightower, eds, The Big Book on Small Heat Shock Proteins. Springer International Publishing, Cham, Switzerland, 2015. pp 119-153

33. McLoughlin F, Basha E, Fowler ME, Kim M, Bordowitz J, Katiyar-Agarwal S, Vierling E. Class I and II small heat shock proteins together with HSP101 protect protein translation factors during heat stress. Plant Physiol. 2016; 172:1221-36.

34. Waters ER, Vierling E. The diversification of plant cytosolic small heat shock proteins preceded the divergence of mosses. Mol Biol Evol. 1999; 16:127-39.

35. Waters ER, Rioflorido I. Evolutionary analysis of the small heat shock proteins in five complete algal genomes. J Mol Evol. 2007; 65:162-74.

36. Waters ER. The evolution, function, structure, and expression of the plant sHSPs. J Exp Bot. 2013; 64:391-403.

37. Li Y, Li Y, Liu Y, Wu Y, Xie Q. The sHSP22 heat shock protein requires the ABI1 protein phosphatase to modulate polar auxin transport and downstream responses. Plant Physiol. 2018;176: 2406-25.

38. Li G, Li J, Hao R, Guo Y. Activation of catalase activity by a peroxisome-localized small heat shock protein Hsp17.6II. J Genet Genomics. 2017; 44: 395-404.

39. Ma W, Guan X, Li J, Pan R, Wang L, Liu F, et al. Mitochondrial small heat shock protein mediates seed germination via thermal sensing. Proc Natl Acad Sci USA. 2019; 116: 4716-21.

40. Heckathorn SA, Downs CA, Sharkey TD, Coleman JS. The small, methionine-rich chloroplast heatshock protein protects photosystem II electron transport during heat stress. Plant Physiol. 1998; 116:439-44.

41. Heckathorn SA, Ryan SL, Baylis JA, Wang DF, Hamilton EW, Cundiff L, et al. In vivo evidence from an Agrostis stolonifera selection genotype that chloroplast small heat-shock proteins can protect photosystem II during heat stress. Funct Plant Biol. 2002;29: 933-44.

42. Shakeel S, UI Haq N, Heckathorn SA, Hamilton EW, Luthe DS. Ecotypic variation in chloroplast small heat-shock proteins and related thermotolerance in Chenopodium album. Plant Physiol Biochem. 2011; 49:898-908.

43. Harndahl U, Hall RB, Osteryoung KW, Vierling E, Bornman JF. Sundby C. The chloroplast small heat shock protein undergoes oxidation-dependent conformational changes and may protect plants from oxidative stress. Cell Stress Chaperones. 1999;4: 129-38. 
44. Chen S, He N, Chen J, Guo F. Identification of core subunits of photosystem II as action sites of HSP21, which is activated by the GUN5-mediated retrograde pathway in Arabidopsis. Plant $\mathrm{J}$. 2017;89: 1106-18.

45. Sedaghatmehr M, Mueller-Roeber B, Balazadeh S. The plastid metalloprotease FtsH6 and small heat shock protein HSP21 jointly regulate thermomemory in Arabidopsis. Nat Commun. 2016;7: 12439.

46. Li Z, Hu Q, Zhou M, Vandenbrink J, Li D, Menchyk N, et al. Heterologous expression of OsSIZ1, a rice SUMO E3 ligase, enhances broad abiotic stress tolerance in transgenic creeping bentgrass. Plant Biotechnol J. 2013; 11: 432-45.

47. Li Z, Yuan S, Jia H, Gao F, Zhou M, Yuan N, et al. Ectopic expression of a cyanobacterial flavodoxin in creeping bentgrass impacts plant development and confers broad abiotic stress tolerance. Plant Biotechnol J. 2016; 15:433-46.

48. Zhao J, Yuan S, Zhou M, Yuan N, Li Z, Hu Q, et al. Transgenic creeping bentgrass overexpressing Osa-miR393a exhibits altered plant development and improved multiple stress tolerance. Plant Biotechnol J. 2018; 17:233-51.

49. Zhou M, Li D, Li Z, Hu Q, Yang C, Zhu L, et Constitutive expression of a miR319 gene alters plant development and enhances salt and drought tolerance in transgenic creeping bentgrass. Plant Physiol. 2013; 161:1375-91.

50. Luo H, Kausch AP, Hu Q, Nelson K, Wipff JK, Fricker CCR, et al. Controlling transgene escape in GM creeping bentgrass. Mol Breed. 2005; 16:185-88.

51. Bart R, Chern M, Park CJ, Battley L, Ronald PC. A novel system for gene slienceing using siRNAs in rice leaf and stem-derived protoplasts. Plant Methods. 2006; 2:13

52. Kim D, Pertea G, Trapnell C, Pimentel H, Kelley R, Salzberg SL. TopHat2: accurate alignment of transcriptomes in the presence of insertions, deletions and gene fusions. Genome Biol. 2013; 14: R36.

53. Trapnell C, Williams BA, Pertea G, Mortazavi A, Kwan G, van Baren MJ, et al. Transcript assembly and quantification by RNA Seq reveals unannotated transcripts and isoform switching during cell differentiation. Nat Biotechnol. 2010; 28:511-15.

54. Schulze SK, Kanwar R, Gölzenleuchter M, Therneau TM, Beutler AS. SERE: single-parameter quality control and sample comparison for RNA-Seq. BMC Genomics. 2012; 13:524.

55. Li Z, Baldwin CM, Hu Q, Liu H, Luo H. Heterologous expression of Arabidopsis $\mathrm{H}^{+}$-pyrophosphatase enhances salt tolerance in transgenic creeping bentgrass (Agrostis stolonifera). Plant Cell Environ. 2010; 33:272-89.

56. Finkelstein R: Abscisic acid synthesis and response. Arabidopsis Book 2013, 11:e0166 http://dx.doi.org/10.1199/tab.0166.

57. Wani SH, Kumar V. Plant stress tolerance: engineering ABA: a Potent phytohormone. Transcriptomics: An Open Access 2015;3: 1000113. 
58. Sah SK, Reddy KR, Li J. Abscisic acid and abiotic stress tolerance in crop plants. Front Plant Sci. 2016; 7: 571.

59. Vierling E, Harris LM, Chen Q. The major low-molecularweight heat-shock protein in chloroplasts shows antigenic conservation among diverse higher-plant species. Mol. Cell. Biol. 1989;9: 461-68.

60. Vierling E. The roles of heat-shock proteins in plants. Annu. Rev. Plant Physiol. Plant Mol. Biol. 1991; 42:579-620.

61. Scharf KD, Berberich T, Ebersberbger I, Nover L. The plant heat stress transcription factor (Hsf) family: structure, function and evolution. Biochim Biophys Acta. 2012; 1819:104-19.

62. Akhtar M, Jaiswal A, Taj G, Jaiswal JP, Qureshi MI, Singh NK. DREB1/CBF transcription factors: their structure, function and role in abiotic stress tolerance in plants. J. Genet. 2012; 91:385-395.

63. Fragkostefanakis S, Röth S, Schleiff E, Scharf KD. Prospects of engineering thermotolerance in crops through modulation of heat stress transcription factor and heat shock protein networks. Plant Cell Environ. 2015;38: 1881-95.

64. Jacob P, Hirt H, Bendahmane A. The heat-shock protein/chaperone network and multiple stress resistance. Plant Biotechnol J. 2017; 15:405-14.

65. Ikeda M, Mitsuda N, Ohme-Takagi M. Arabidopsis HsfB1 and HsfB2b act as repressors of the expression of heat-inducible Hsfs but positively regulate the acquired thermotolerance. Plant Physiol. 2011; 157:1243-54.

66. Ashraf M, Yang S, Wu R, Wang Y, Hussain A, Noman A, et al. Capsicum annuum HsfB2a positively regulates the response to Ralstonia solanacearum infection or high temperature and high humidity forming transcriptional cascade with CaWRKY6 and CaWRKY40, Plant Cell Physiol. 2018; 59:260823.

67. Guan Q, Yue X, Zeng H, Zhu J. The protein phosphatase RCF2 and its interacting partner NAC019 are critical for heat stress-responsive gene regulation and thermotolerance in Arabidopsis. Plant Cell. $2014 ; 26: 438-53$.

68. Zhuang L, Cao W, Wang J, Yang Z, Huang B. Characterization and Functional Analysis of FaHsfC1b from Festuca arundinacea Conferring Heat Tolerance in Arabidopsis. Int J Mol Sci. 2018; 19:2702.

69. Zhang, D. Abscisic Acid: Metabolism, Transport and Signaling. New York, NY: Springer. 2014.

70. Bartels D, Sunkar R. Drought and salt tolerance in plants. Crit Rev Plant Sci. 2005; 24:23-58.

71. Yamaguchi-Shinozaki K, Shinozaki K. Transcriptional regulatory networks in cellular responses and tolerance to dehydration and cold stresses. Annu Rev Plant Biol. 2006; 57:781-803.

72. Shao HB, Liang ZS, Shao MA. LEA proteins in higher plants: structure, function, gene expression and regulation. Colloids Surf B Biointerfaces. 2005; 45:131-35.

73. Xiao $B$, Huang $Y$, Tang N, Xiong L. Over-expression of a LEA gene in rice improves drought resistance under the field conditions. Theor. Appl. Genet. 2007; 115:35-46.

74. Tang N, Ma S, Zong W, Yang N, Lv Y, Yan C, et al. MODD mediates deactivation and degradation of OsbZIP46 to negatively regulate ABA signaling and drought resistance in rice. Plant Cell. 2016; 28 : 
2161-77.

75. Huang L, Zhang M, Jia J, Zhao X, Huang X, Ji E, et al. An atypical late embryogenesis abundant protein OsLEA5 plays A positive role in ABA-induced antioxidant defense in Oryza Sativa L. Plant Cell Physiol. 2018; 59:916-29.

76. Magwanga RO, Lu P, Kirungu JN, Dong Q, Hu Y, Zhou Z, et al. Cotton late embryogenesis abundant (LEA2) genes promote root growth and confers drought stress tolerance in transgenic Arabidopsis thaliana. G3-Genes Genomes Genetics. 2018; 8:2781-2803

77. Ambawat S, Sharma P, Yadav NR, Yadav RC. MYB transcription factor genes as regulators for plant responses: an overview. Physiol Mol Biol Plants. 2013; 19:307-21.

78. Baldoni E, Genga A, Cominelli E. Plant MYB transcription factors: their role in drought response mechanisms. Int J Mol Sci. 2015; 16:15811-51.

79. Li C, Ng CKY, Fan LM. MYB transcription factors, active players in abiotic stress signaling. Environ Exp Bot. 2015; 114:80-91.

80. Yu Y, Ni Z, Chen Q, Qu Y. The wheat salinity-induced R2R3-MYB transcription factor TaSIM confers salt stress tolerance in Arabidopsis thaliana. Biochem Biophys Res Commun. 2017; 491:642-48.

81. Wei Q, Luo Q, Wang R, Zhang F, He Y, Zhang Y, et al. A Wheat R2R3-type MYB Transcription Factor TaODORANT1 Positively Regulates Drought and Salt Stress Responses in Transgenic Tobacco Plants. Front Plant Sci. 2017; 8: 1374.

82. Gao F, Zhou J, Deng R, Zhao H, Li C, Chen H, et al. Overexpression of a tartary buckwheat R2R3-MYB transcription factor gene, FtMYB9, enhances tolerance to drought and salt stresses in transgenic Arabidopsis. J Plant Physiol. 2017;214: 81-90.

83. Dong J, Chen C, Chen Z. Expression profiles of the Arabidopsis WRKY gene superfamily during plant defense response. Plant Mol Biol. 2003; 51: 21-37.

84. Rushton DL, Tripathi P, Rabara RC, Lin J, Ringler P, Boken AK, et al. WRKY transcription factors: Key components in abscisic acid signalling. Plant Biotechnol J. 2012; 10: 2-11.

85. Schluttenhofer $C$, Yuan L. Regulation of specialized metabolism by WRKY transcription factors. Plant Physiol. 2015;167: 295-306.

86. Li S, Fu Q, Chen L, Huang W, Yu D. Arabidopsis thaliana WRKY25, WRKY26, and WRKY33 coordinate induction of plant thermotolerance. Planta. 2011;233: 1237-52.

87. He GH, Xu JY, Wang YX, Liu JM, Li PS, Chen M, et al. Drought-responsive WRKY transcription factor genes TaWRKY1 and TaWRKY33 from wheat confer drought and/or heat resistance in Arabidopsis. BMC Plant Biol. 2016; 16: 116.

88. Yan H, Jia H, Chen X, Hao L, An H, Guo X. The cotton WRKY transcription factor GhWRKY17 functions in drought and salt stress in transgenic Nicotiana benthamiana through ABA signaling and the modulation of reactive oxygen species production. Plant Cell Physiol. 2014;55: 2060-76.

89. Nakashima K, Shinwari ZK, Sakuma Y, Seki M, Miura, Shinozaki K, Yamaguchi-Shinozaki K. Organization and expression of two Arabidopsis DREB2 genes encoding DRE-binding proteins 
involved in dehydration and high-salinity-responsive gene expression. Plant Mol Biol. 2000; 42:65765.

90. Sakuma Y, Liu Q, Dubouzet JG, Abe H, Shinozaki K, Yamaguchi-Shinozaki K. DNA-binding specificity of the ERF/AP2 domain of Arabidopsis DREBs, transcription factors involved in dehydration- and cold-inducible gene expression. Biochem Biophys Res Commun. 2002; 290:998-1009.

91. Sakuma Y, Maruyama K, Osakabe Y, Qin F, Seki M, Shinozaki K, et al. Functional analysis of an Arabidopsis transcription factor, DREB2A, involved in drought-responsive gene expression. Plant Cell. 2006; 18:1292-1309.

92. Sakuma Y, Maruyama K, Qin F, Osakabe Y, Shinozaki K, Yamaguchi-Shinozaki K. Dual function of an Arabidopsis transcription factor DREB2A in water-stress-responsive and heat-stress-responsive gene expression. Proc Natl Acad Sci USA.2006;103:18822-27.

93. Chen H, Hwang JE, Lim CJ, Kim DY, Lee SY, Lim CO. Arabidopsis DREB2C functions as a transcriptional activator of HsfA3 during the heat stress response. Biochem Biophys Res Commun. 2010; 401:238-44.

94. Agarwal PK, Jha B. Transcription factors in plants and ABA dependent and independent abiotic stress signaling. Biologia Plantarum. 2010; 54:201-12.

95. Lata C, Prasad M. Role of DREBs in regulation of abiotic stress responses in plants. J Exp Bot. 2011; 62:4731-38.

96. Yoshida T, Mogami J, Yamaguchi-Shinozaki K. ABA-dependent and ABA-independent signaling in response to osmotic stress in plants. Curr Opin Plant Biol. 2014; 21:133-39.

97. Maruyama K, Sakuma Y, Kasuga M, Ito Y, Seki M, Goda H, et al. Identification of cold-inducible downstream genes of the Arabidopsis DREB1A/CBF3 transcriptional factor using two microarray systems. Plant J. 2004; 38:982-93.

98. Maruyama K, Takeda M, Kidokoro S, Yamada K, Sakuma Y, Urano K, et al. Metabolic pathways involved in cold acclimation identified by integrated analysis of metabolites and transcripts regulated by DREB1A and DREB2A. Plant Physiol. 2009; 150:1972-80.

99. Pellegrineschi A, Reynolds M, Pacheco M, Brito RM, Almeraya R, Yamaguchi-Shinozaki K, er al. Stress-induced expression in wheat of the Arabidopsis thaliana DREB1A gene delays water stress symptoms under greenhouse conditions. Genome. 2004; 47:493-500.

100. Suo H, Ma Q, Ye K, Yang C, Tang Y, Hao J, et al. Overexpression of AtDREB1A causes a severe dwarf phenotype by decreasing endogenous gibberellin levels in soybean [Glycine max (L.) Merr]. PLoS ONE, 2012;7: e45568.

101. Bhatnagar-Mathur P, Rao JS, Vadez V, Dumbala SR, Rathore A, Yamaguchi-Shinozaki K, et al. Transgenic peanut overexpressing the DREB1A transcription factor has higher yields under drought stress. Mol. Breed. 2014; 33: 327-40.

102. Wei T, Deng K, Gao Y, Liu Y, Yang M, Zhang L, et al. Arabidopsis DREB1B in transgenic Salvia miltiorrhiza increased tolerance to drought stress without stunting growth. Plant Physiol Biochem. 2016;104: 17-28. 
103. Ito Y, Katsura K, Maruyama K, Taji T, Kobayashi M, Seki M, et al. Functional analysis of rice DREB1/CBF-type transcription factors involved in cold-responsive gene expression in transgenic rice. Plant Cell Physiol. 2006;47:141-53.

104. Schramm F, Larkindale J, Kiehlmann E, Ganguli A, Englich G, Vierling E, et al. A cascade of transcription factor DREB2A and heat stress transcription factor HsfA3 regulates the heat stress response of Arabidopsis. Plant J 2008; 53:264-74.

105. Büttner M, Singh KB. Arabidopsis thaliana ethylene-responsive element binding protein (AtEBP), an ethylene-inducible, GCC box DNA-binding protein interacts with an ocs element binding protein. Proc Natl Acad Sci USA. 1997; 94: 5961-66.

106. Zarei A, Korbes AP, Younessi P, Montiel G, Champion A, Memelink J. Two GCC boxes and AP2/ERFdomain transcription factor ORA59 in jasmonate/ethylene-mediated activation of the PDF1.2 promoter in Arabidopsis. Plant Mol Biol. 2011; 75:321-31.

107. Licausi F, Ohme-Takagi M, Perata P. APETALA2/Ethylene Responsive Factor (AP2/ERF) transcription factors: mediators of stress responses and developmental programs. New Phytol. 2013;199: 639-49.

108. Li Z, Tian Y, Xu J, Fu X, Gao J, Wang B, et al. A tomato ERF transcription factor, SIERF84, confers enhanced tolerance to drought and salt stress but negatively regulates immunity against Pseudomonas syringae pv. tomato DC3000. Plant Physiol Biochem. 2018; 132:683-95.

109. Nie J, Wen C, Xi L, Lv S, Zhao Q, Kou Y, et al. The AP2/ERF transcription factor CmERF053 of chrysanthemum positively regulates shoot branching, lateral root, and drought tolerance. Plant Cell Rep. 2018; 37:1049-60.

110. Qin L, Wang L, Guo Y, Li Y, Ümüt H, Wang Y. An ERF transcription factor from Tamarix hispida, ThCRF1, can adjust osmotic potential and reactive oxygen species scavenging capability to improve salt tolerance. Plant Sci. 2017;265: 154-66.

111. Kim KN, Cheong YH, Gupta R, Luan S. Interaction specificity of Arabidopsis calcineurin B-like calcium sensors and their target kinases. Plant Physiol. 2000;124: 1844-53.

112. Takahashi S, Katagiri T, Yamaguchi-Shinozaki K, Shinozaki K. An Arabidopsis gene encoding a Ca2+binding protein is induced by abscisic acid during dehydration. Plant Cell Physiol. 2000; 41: 898903.

113. Gao D, Knight MR, Trewavas AJ, Sattelmacher B, Plieth C. Self-reporting Arabidopsis expressing pH and $[\mathrm{Ca} 2+]$ indicators unveil ion dynamics in the cytoplasm and in the apoplast under abiotic stress. Plant Physiol. 2004;134: 898-908.

114. Gong D, Guo Y, Schumaker KS, Zhu JK. The SOS3 family of calcium sensors and SOS2 family of protein kinases in Arabidopsis. Plant Physiol. 2004; 134: 919-26.

115. Kolukisaoglu U, Wein S, Blazevic D, Batistic O, Kudla J. Calcium sensors and their interacting protein kinases: genomics of the Arabidopsis and rice CBL-CIPK signaling networks. Plant Physiol. 2004; 134: 43-58.

116. Hashimoto K, Kudla J. Calcium decoding mechanisms in plants. Biochimie. 2011;93: 2054-59.

117. Reddy AS. Calcium: silver bullet in signaling. Plant Sci. 2001;160: 381-404. 
118. Jiang Z, Zhu S, Ye R, Xue Y, Chen A, An L, et al. Relationship between $\mathrm{NaCl}$ - and $\mathrm{H}_{2} \mathrm{O}_{2}$-induced cytosolic $\mathrm{Ca}^{2+}$ increases in response to stress in Arabidopsis. PloS One. 2013; 8: e76130.

119. Delk NA, Johnson KA, Chowdhury NI, Braam J. CML24, regulated in expression by diverse stimuli, encodes a potential $\mathrm{Ca} 2+$ sensor that functions in responses to abscisic acid, daylength, and ion stress. Plant Physiol. 2005;139: 240-53.

120. Yamaguchi T, Aharon GS, Sottosanto JB. Blumwald E. Vacuolar $\mathrm{Na}+/ \mathrm{H}+$ antiporter cation selectivity is regulated by calmodulin from within the vacuole in a $\mathrm{Ca} 2+-$ and $\mathrm{pH}$-dependent manner. Proc Natl Acad Sci USA. 2005;102: 16107-12.

121. Magnan F, Ranty B, Charpenteau M, Sotta B, Galaud JP, Aldon D. Mutations in AtCML9, a calmodulinlike protein from Arabidopsis thaliana, alter plant responses to abiotic stress and abscisic acid. Plant J. 2008; 56: 575-89.

122. Qiao B, Zhang $Q$, Liu D, Wang $H$, Yin J, Wang R, et al. A calcium-binding protein, rice annexin OsANN1, enhances heat stress tolerance by modulating the production of $\mathrm{H}_{2} \mathrm{O}_{2}$. J Exp Bot. 2015; 66:5853-66.

123. Shiu SH, Bleecker AB. Plant receptor-like kinase gene family: Diversity, function, and signaling. Sci STKE. 2001: re22.

124. Wei Z, Li J. Receptor-like protein kinases: Key regulators controlling root hair development in Arabidopsis thaliana. J Integr Plant Biol. 2018; 60: 841-50.

125. Lim CW, Yang SH, Shin KH, Lee SC, Kim SH. The AtLRK10L1.2, Arabidopsis, ortholog of wheat LRK10, is involved in ABA-mediated signaling and drought resistance. Plant Cell Rep. 2015; 34:44755.

126. Sun XL, Sun M, Luo X, Ding XD, Cai H, Bai X, et al. Erratum to: a Glycine soja, ABA-responsive receptor-like cytoplasmic kinase, GsRLCK, positively controls plant tolerance to salt and drought stresses. Planta. 2013; 237:1527-45.

127. Vaid N, Pandey P, Srivastava VK, Tuteja N. Pea lectin receptor-like kinase functions in salinity adaptation without yield penalty, by alleviating osmotic and ionic stresses and upregulating stressresponsive genes. Plant Mol Biol. 2015; 88:1-14.

128. de Lorenzo L, Merchan F, Laporte P, Thompson R, Clarke J, Sousa C, et al. A novel plant leucine-rich repeat receptor kinase regulates the response of Medicago truncatula roots to salt stress. Plant Cell. 2009; 21:668-80.

129. Takatsuji H. Zinc-finger proteins: the classical zinc finger emerges in contemporary plant science. Plant Mol Biol. 1999;39: 1073-78.

130. Kim SH, Ahn YO, Ahn M, Jeong JC, Lee H, Kwak S. Cloning and characterization of an Orange gene that increases carotenoid accumulation and salt stress tolerance in transgenic sweetpotato cultures. Plant Physiol Biochem. 2013; 70: 445-54.

131. Muthamilarasan M, Bonthala VS, Mishra AK, Khandelwal R, Khan Y, Roy R, et al. C2H2 type of zinc finger transcription factors in foxtail millet define response to abiotic stresses. Funct Integr Genomic. 2014; 14: 531-43. 
132. Yue X, Que Y, Xu L, Deng S, Peng Y, Talbot NJ, et al. ZNF1 encodes a putative $\mathrm{C} 2 \mathrm{H} 2$ zinc-finger protein essential for appressorium differentiation by the rice blast fungus Magnaporthe oryzae. Mol Plant Microbe Interact. 2016;29: 22-35.

133. Chen J, Yang L, Yan X, Liu Y, Wang R, Fan T, et al. Zinc-Finger Transcription Factor ZAT6 Positively Regulates Cadmium Tolerance through the Glutathione-Dependent Pathway in Arabidopsis. Plant Physiol. 2016; 171:707-19.

134. Ciftci-Yilmaz S, Morsy MR, Song L, Coutu A, Krizek BA, Lewis MW, et al. The EAR-motif of the Cys2/His2-type zinc finger protein Zat7 plays a key role in the defense response of Arabidopsis to salinity stress. J Biol Chem. 2007; 282: 9260-68.

135. Sakamoto H, Maruyama K, Sakuma Y, Meshi T, Iwabuchi M, Shinozaki K, et al. Arabidopsis Cys2/His2-type zinc-finger proteins function as transcription repressors under drought, cold, and high-salinity stress conditions. Plant Physiol. 2004; 136:2734-46.

136. Mittler R, Kim Y, Song L, Coutu J, Coutu A, Ciftci-Yilmaz S, et al. Gain- and loss-of-function mutations in Zat10 enhance the tolerance of plants to abiotic stress. FEBS Lett. 2006; 580:6537-42.

137. Rossel JB, Wilson PB, Hussain D, Woo NS, Gordon MJ, Mewett OP, et al. Systemic and intracellular responses to photooxidative stress in Arabidopsis. Plant Cell. 2007; 19:4091-110.

138. Nguyen XC, Kim SH, Hussain S, An J, Yoo Y, Han HJ, et al. A positive transcription factor in osmotic stress tolerance, ZAT10, is regulated by MAP kinases in Arabidopsis. J Plant Biol. 2016;59: 55-61.

139. Song H, Zhao R, Fan P, Wang X, Chen X, Li Y. Overexpression of AtHsp90.2, AtHsp90.5 and AtHsp90.7 in Arabidopsis thaliana enhances plant sensitivity to salt and drought stresses. Planta. 2009; 229:955-64.

\section{Tables}

Table 1. Annotation of genes up-regulated or down-regulated in AsHSP26.8a overexpressing TG Arabidopsis compared to WT controls. Significant differences were corrected with FDR $<0.01$ and expression ratio $\geq 2$, (FC, fold change) 


\begin{tabular}{|c|c|c|}
\hline \multirow{2}{*}{$\begin{array}{l}\text { ene \#ID } \\
\text { nal proteins }\end{array}$} & \multirow{2}{*}{$\log 2 \mathrm{FC}$} & \multirow[t]{2}{*}{ nr_annotation } \\
\hline & & \\
\hline \multicolumn{3}{|c|}{ nscription factor } \\
\hline$\Gamma 1 \mathrm{G} 68840$ & -1.12 & AP2-EREBP family, RAVE subfamily protein RAV2 \\
\hline Г4G25490 & -6.80 & dehydration-responsive element-binding protein $1 \mathrm{~B}$ \\
\hline Г3G15210 & -2.12 & ethylene-responsive transcription factor 4 \\
\hline Г5G47230 & -2.49 & ethylene-responsive transcription factor 5 \\
\hline Г5G53290 & -2.27 & ethylene-responsive transcription factor CRF3 \\
\hline Г3G50260 & -2.03 & ethylene-responsive transcription factor ERF011 \\
\hline Г1G77640 & -3.41 & ethylene-responsive transcription factor ERF013 \\
\hline Г1G22190 & -1.81 & ethylene-responsive transcription factor ERF058 \\
\hline Г5G61600 & -2.52 & ethylene-responsive transcription factor ERF104 \\
\hline Г5G51190 & -4.49 & ethylene-responsive transcription factor ERF105 \\
\hline Г5G62020 & -1.50 & heat stress transcription factor $\mathrm{B}-2 \mathrm{a}$ \\
\hline ГЗ3 24520 & -1.68 & heat stress transcription factor C-1 \\
\hline Г5G49330 & 1.39 & myb domain protein 111 \\
\hline Г1G18570 & -1.31 & myb domain protein 51 \\
\hline Г4G37260 & -1.35 & myb domain protein 73 \\
\hline Г3G50060 & -2.70 & myb domain protein 77 \\
\hline Г1G25550 & -1.63 & myb-like transcription factor-like protein \\
\hline Г5G67300 & -1.39 & transcription factor MYB44 \\
\hline Г1G69490 & -1.26 & NAC transcription factor protein family \\
\hline Г4G31800 & -1.18 & WRKY DNA-binding protein 18 \\
\hline Г1G62300 & -1.16 & WRKY transcription factor 6 \\
\hline Г3G46620 & -3.92 & $\mathrm{C} 3 \mathrm{H} 4$ type zinc finger protein \\
\hline Г1G51700 & -1.19 & DOF zinc finger protein 1 \\
\hline Г5G59820 & -4.87 & high light responsive zinc finger protein ZAT12 \\
\hline Г3G52800 & -1.56 & $\begin{array}{l}\text { zinc finger A20 and AN1 domain-containing stress-associated } \\
\text { protein } 6\end{array}$ \\
\hline Г1G27730 & -3.74 & zinc finger protein STZ/ZAT10 \\
\hline Г2G37430 & -5.33 & zinc finger protein ZAT11 \\
\hline Г5G04340 & -2.28 & zinc finger protein ZAT6 \\
\hline Г3G46090 & -4.18 & zinc finger protein ZAT7 \\
\hline$\Gamma 5 G 67450$ & -3.06 & zinc-finger protein 1 \\
\hline \multicolumn{3}{|l|}{ nalling } \\
\hline Г5G49480 & -1.41 & Ca2+-binding protein 1 \\
\hline Г5G37770 & -2.55 & calcium-binding protein CML24 \\
\hline Г1G76650 & -4.92 & calcium-binding protein CML38 \\
\hline Г5G62570 & -1.17 & calmodulin binding protein-like protein \\
\hline Г1G66400 & -3.17 & calmodulin like 23 \\
\hline Г2G41100 & -1.02 & calmodulin-like protein 4 \\
\hline ГЗ3G25600 & -1.50 & putative calcium-binding protein CML16 \\
\hline Г3G29000 & -4.55 & putative calcium-binding protein CML30 \\
\hline Г5G39670 & -2.02 & putative calcium-binding protein CML45 \\
\hline Г3G10300 & -1.02 & putative calcium-binding protein CML49 \\
\hline \multicolumn{3}{|l|}{ ase } \\
\hline Г4G23190 & -1.43 & cysteine-rich receptor-like protein kinase 11 \\
\hline Г2G19190 & -2.16 & FLG22-induced receptor-like kinase 1 \\
\hline Г1G67470 & -1.37 & inactive serine/threonine-protein kinase \\
\hline Г5G01540 & -1.60 & lectin receptor kinase A4.1 \\
\hline Г1G33610 & -1.28 & leucine-rich repeat (LRR) family protein \\
\hline Г1G51790 & -1.02 & leucine-rich repeat protein kinase-like protein \\
\hline Г3G47090 & -1.02 & leucine-rich repeat protein kinase-like protein \\
\hline
\end{tabular}


Г2G30040

Г1G51890

Г2G44830

Г3G57640

Г4G11521

Г4G04540

Г1G51800

Г1G74360

Г1G61370

Г1G16130
-2.38 mitogen-activated protein kinase kinase kinase 14

-1.73 probable LRR receptor-like protein kinase

1.01 protein kinase

-1.24 protein kinase family protein

-1.26 putative cysteine-rich receptor-like protein kinase 34

-2.83 putative cysteine-rich receptor-like protein kinase 39

-1.51 putative leucine-rich repeat protein kinase

-1.12 putative LRR receptor-like serine/threonine-protein kinase

-1.21 S-locus lectin protein kinase family protein

-1.09 wall-associated receptor kinase-like 2

tion protein

ochrome P450

ГCG00730

-1.68 cytochrome b6/f complex subunit IV

Г4G31500

-1.07 cytochrome P450 83B1

Г4G22710

-2.44 cytochrome P450, family 706, subfamily A, polypeptide 2

Г4G12320

1.32 cytochrome P450, family 706, subfamily A, polypeptide 6

Г5G57220

$-1.43$ cytochrome P450, family 81 , subfamily $\mathrm{F}$, polypeptide 2

Г2G27690

$-1.56$ cytochrome P450, family 94, subfamily C, polypeptide 1

Г1G65690

-1.51 late embryogenesis abundant (LEA) hydroxyproline-rich

$\Gamma 4 \mathrm{G} 23610$

-2.52 late embryogenesis abundant hydroxyproline-rich glycoprotein

Г3G54200

$-1.07$

late embryogenesis abundant hydroxyproline-rich glycoprotein

bohydrate metabolism-related

ins

Г3G09020

-1.37 alpha 1,4-glycosyltransferase family protein

Г5G26340

$-1.37$

$-2.66$

sugar transport protein 13

Г5G18840

sugar transporter ERD6-like 16

Г3G49790

$-1.18$

Carbohydrate-binding protein

rogen metabolism-related

ins

Г1G02920

-1.26 glutathione S-transferase 7/11

Г2G02930

-1.48 glutathione S-transferase F3

Г5G62480

-2.05 glutathione S-transferase tau 9

Г5G02780

-1.78 glutathione transferase lambda 1

Г1G77760

$-1.38$

nitrate reductase [NADH]

-1.61 aspartyl protease family protein

Г1G66180

Г5G19120

$-1.14$

$-1.03$

aspartyl protease family protein

Г2G38860

Г4G22470

$-1.24$

Г4G14290

protease I (pfpI)-like protein YLS5

protease inhibitor/seed storage/lipid transfer protein (LTP) family protein

4.42 alpha/beta-hydrolase family protein

Г1G02660

$-1.37$

alpha/beta-Hydrolases superfamily protein

Г3G05200

$-1.06$

E3 ubiquitin-protein ligase ATL6

Г3G52450

dation-reduction process

-2.75 E3 ubiquitin-protein ligase PUB22

Г3G09940

-1.38 monodehydroascorbate reductase (NADH)

Г4G37925

1.01

$-1.27$

$\mathrm{NAD}(\mathrm{P}) \mathrm{H}$-quinone oxidoreductase subunit $\mathrm{M}$

Г4G11290

peroxidase 39

Г3G47430

1.25

peroxisomal membrane protein $11 \mathrm{~B}$

rgy 
Table 2. Differentially expressed genes in AsHSP26.8a overexpression transgenic and wild type Arabidopsis plants by qRT-PCR analysis.

\begin{tabular}{ccc}
\hline Gene & \multicolumn{2}{c}{ TG/WT (log2 FC) } \\
\cline { 2 - 3 } & Digital expression & qRT-PCR \\
\hline DREB1B & -6.80 & -6.35 \\
ERF105 & -4.49 & -4.82 \\
HSFB2a & -1.68 & -2.53 \\
HSFC1 & -1.50 & -2.17 \\
\hline
\end{tabular}

\section{Figures}




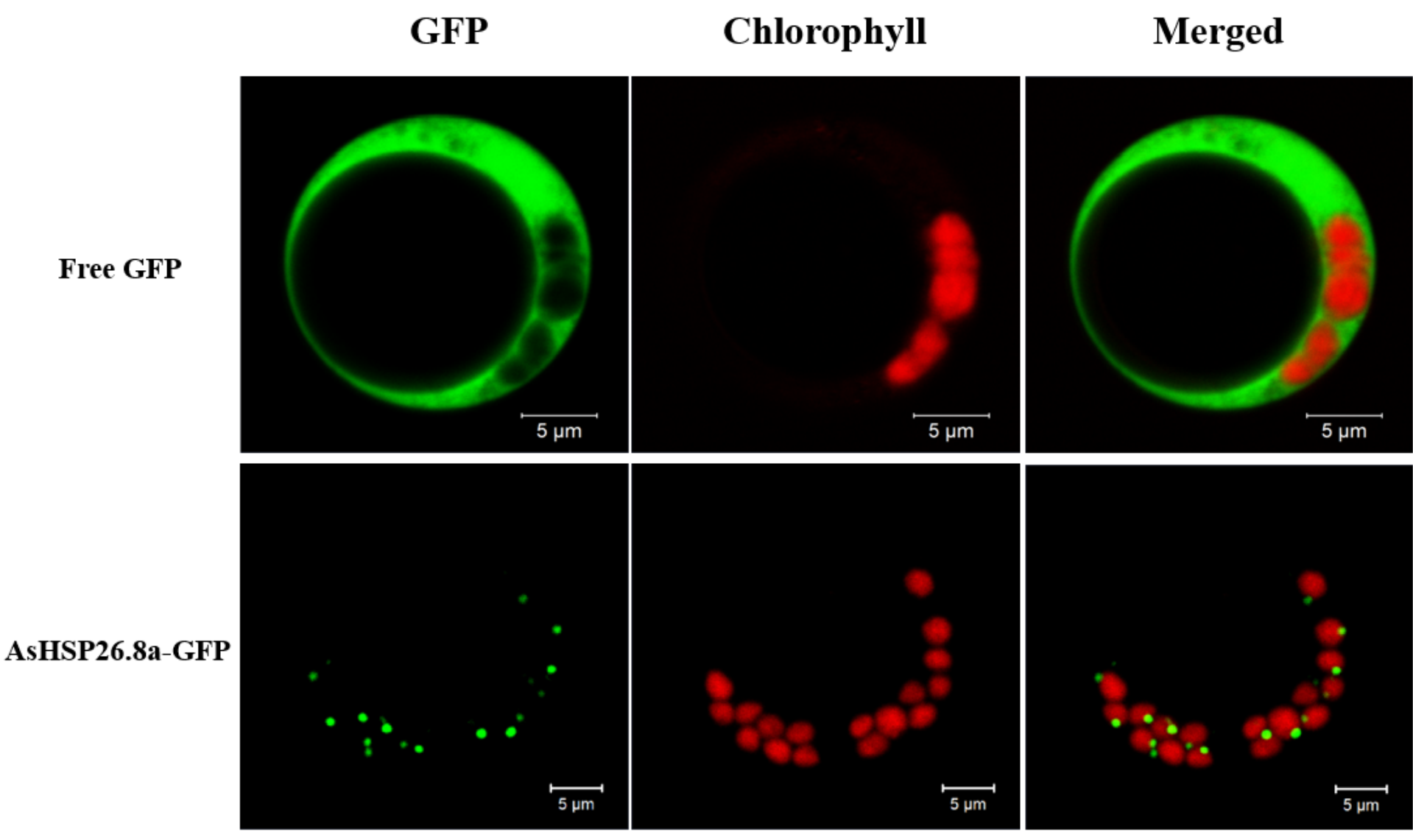

Fig. 1

\section{Figure 1}

Subcellular localization of AsHSP26.8a protein. Free GFP, control with empty vector; AsHSP26.8a-GFP, AsHSP26.8a-GFP fusion. Bars $=5 \mu \mathrm{m}$. 


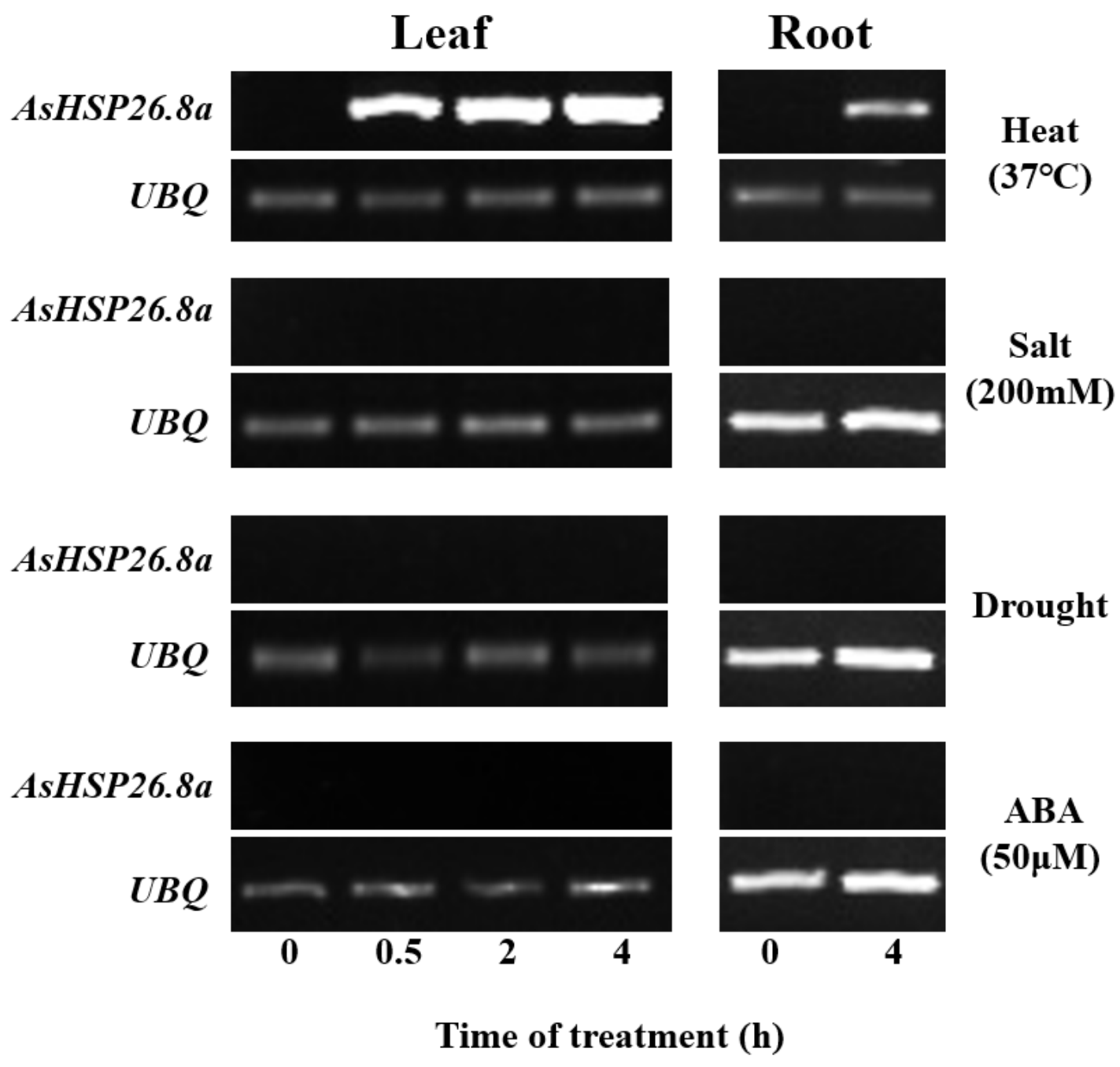

Fig. 2

\section{Figure 2}

Semi-quantitative RT-PCR analysis of AsHSP26.8a expression profile in leaf (left) and root (right) tissues under heat $\left(37^{\circ} \mathrm{C}\right)$, salt $(200 \mathrm{mM} \mathrm{NaCl})$, Drought, $\mathrm{ABA}(50 \mu \mathrm{M})$ treatment. Leaf samples were collected at 0 , $0.5,2$ and $4 \mathrm{~h}$ after stress treatment and root samples were collected at 0 and $4 \mathrm{~h}$ after stress treatment. Total RNA was isolated using Trizol and $2 \mu \mathrm{g}$ total RNA was used for reverse transcription by using reverse transcriptase II (NEB, USA). Creeping bentgrass ubiquitin gene AsUBQ was used as the endogenous control. The gel images were cropped to only retain PCR products. All original, full-length gel images were included as additional files in the supplementary materials. The PCR process: $95^{\circ} \mathrm{C}$ for 5 min, 30 cycles of $95^{\circ} \mathrm{C}$ for $30 \mathrm{~s}, 65^{\circ} \mathrm{C}$ for $30 \mathrm{~s}, 72^{\circ} \mathrm{C}$ for $30 \mathrm{~s}$, for AsHSP26.8a; $95^{\circ} \mathrm{C}$ for $5 \mathrm{~min}, 25$ cycles of $95^{\circ} \mathrm{C}$ for $30 \mathrm{~s}, 60^{\circ} \mathrm{C}$ for $30 \mathrm{~s}, 72^{\circ} \mathrm{C}$ for $30 \mathrm{~s}$, for AsUBQ. 
A

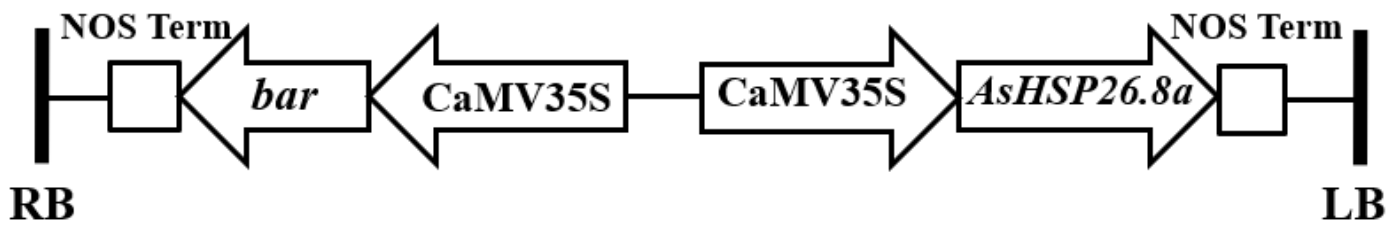

B

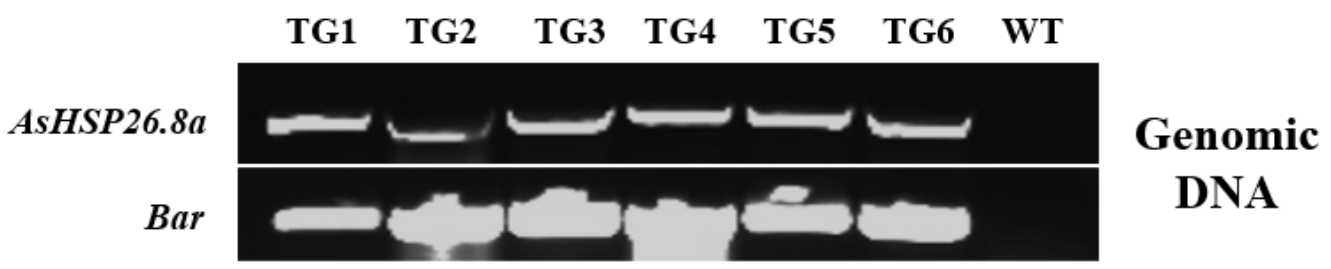

C

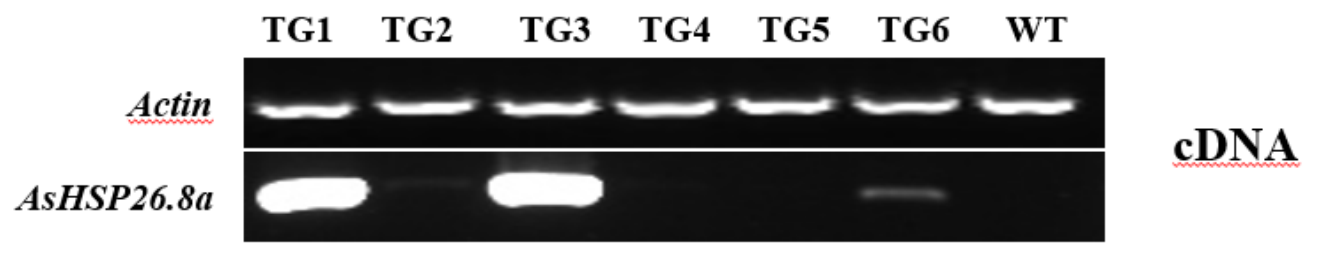

Fig. 3

Figure 3

Generation and molecular analysis of the AsHSP26.8a transgenic (TG) Arabidopsis thaliana. A, Schematic diagram of the AsHSP26.8a chimeric gene expression construct, p35S-AsHSP26.8a/p35S-bar. The AsHSP26.8a gene and an herbicide resistance gene, bar, are both under the control of the CaMV 35S promoter. RB, right border; LB, left border. B, PCR analysis of the AsHSP26.8a and bar gene in wild type (WT) and TG plants to detect transgene insertion in the Arabidopsis thaliana genome and transcription. Actin gene AtActin1 was used as the endogenous control. The gel images were cropped to only retain PCR products. All original, full-length gel images were included as additional files in the supplementary materials. 

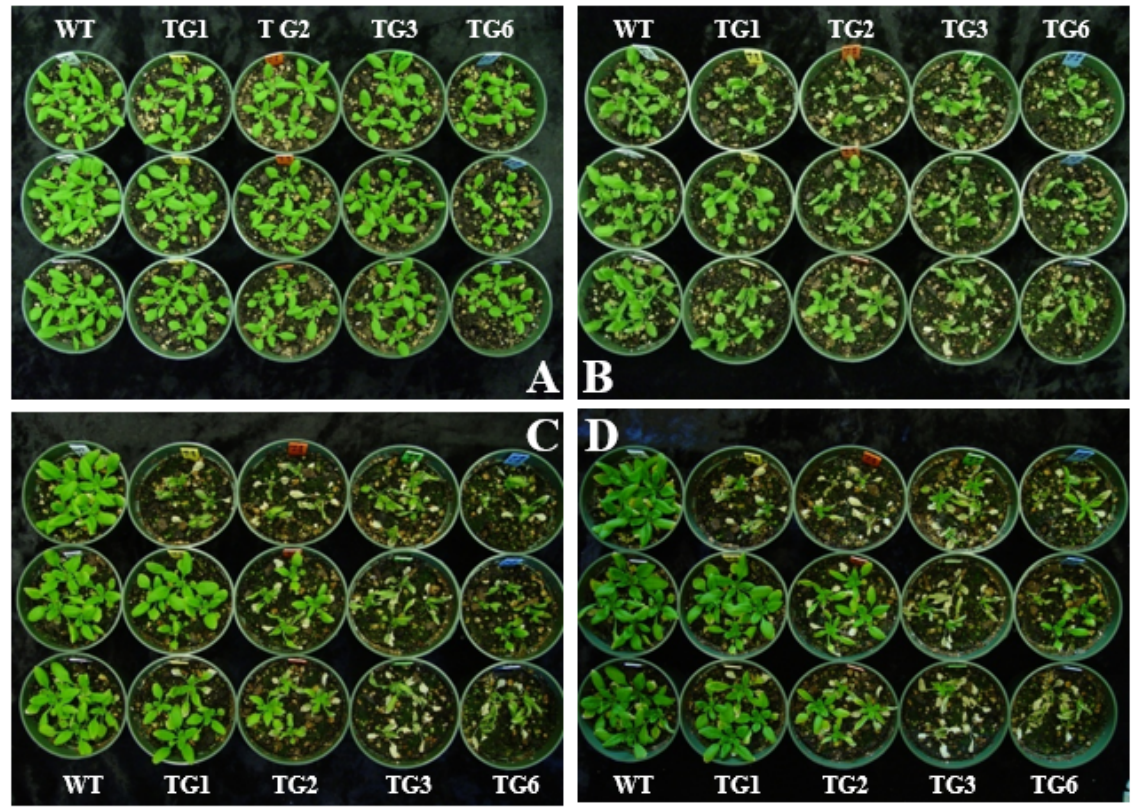

G

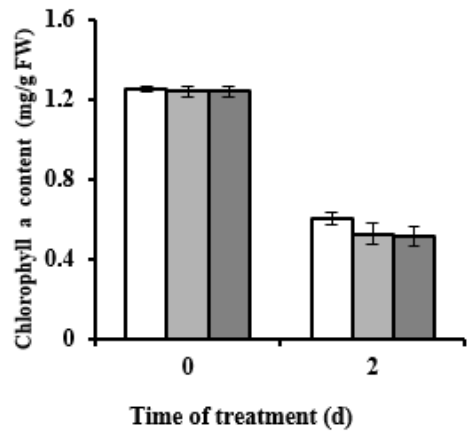

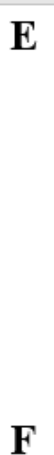

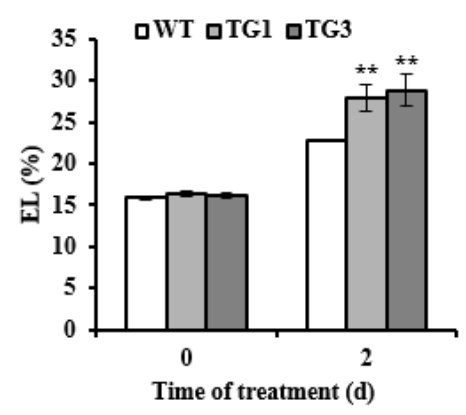

$\mathbf{F}$
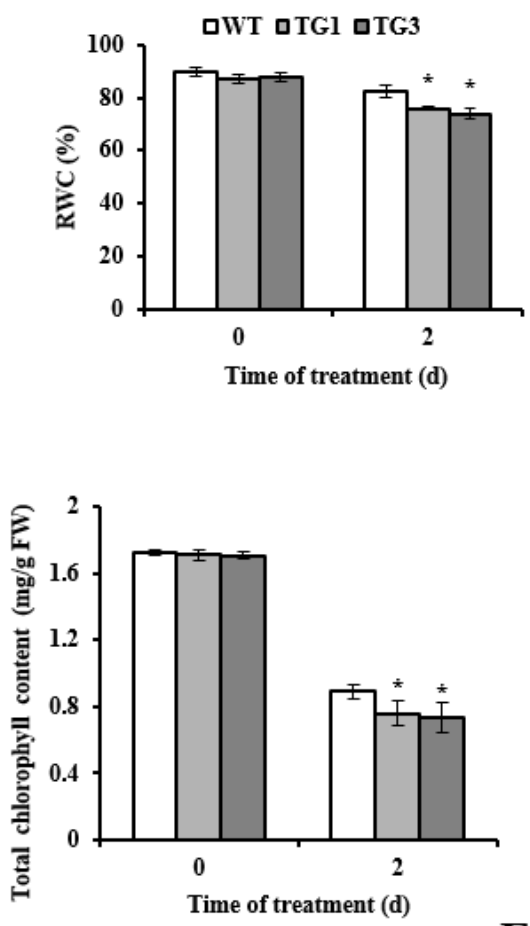

Fig. 4

\section{Figure 4}

Generation and molecular analysis of the AsHSP26.8a transgenic (TG) Arabidopsis thaliana. A, Schematic diagram of the AsHSP26.8a chimeric gene expression construct, p35S-AsHSP26.8a/p35S-bar. The AsHSP26.8a gene and an herbicide resistance gene, bar, are both under the control of the CaMV 35S promoter. RB, right border; LB, left border. B, PCR analysis of the AsHSP26.8a and bar gene in wild type (WT) and TG plants to detect transgene insertion in the Arabidopsis thaliana genome and transcription. Actin gene AtActin1 was used as the endogenous control. The gel images were cropped to only retain PCR products. All original, full-length gel images were included as additional files in the supplementary materials. 
$\mathbf{A}$
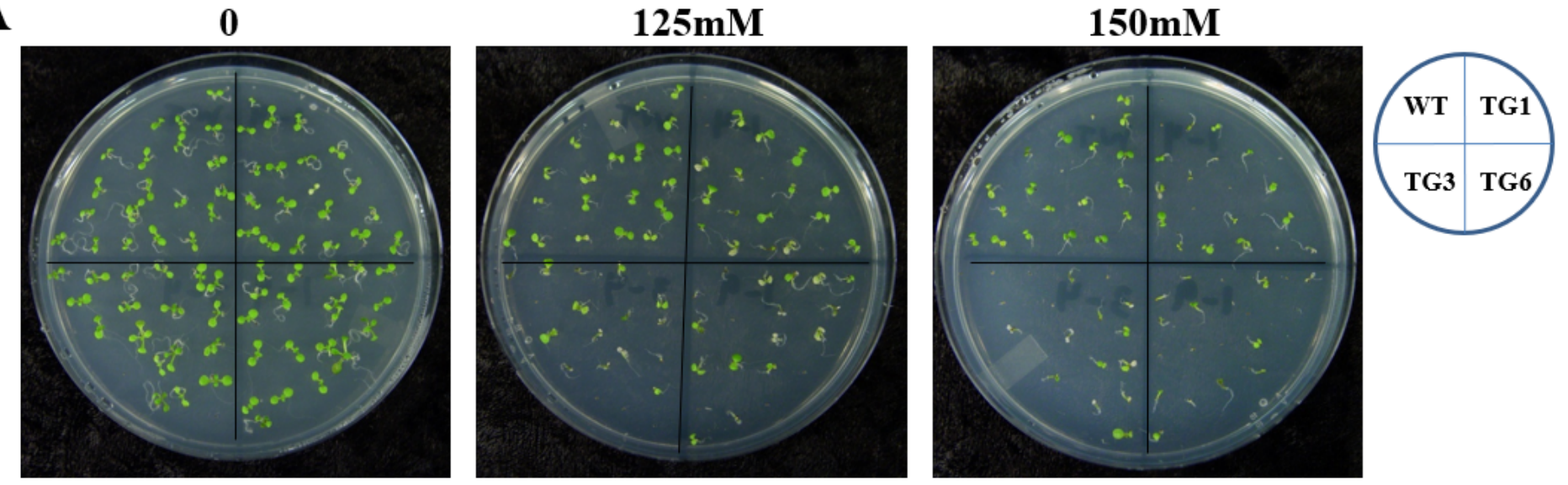

$\because$ WT $\square$ TG1 $\square$ TG3 $\square$ TG6

B

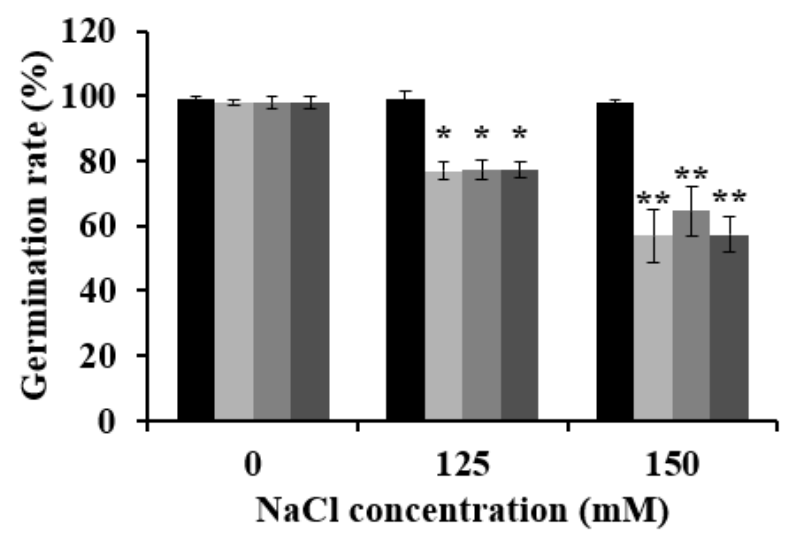

C

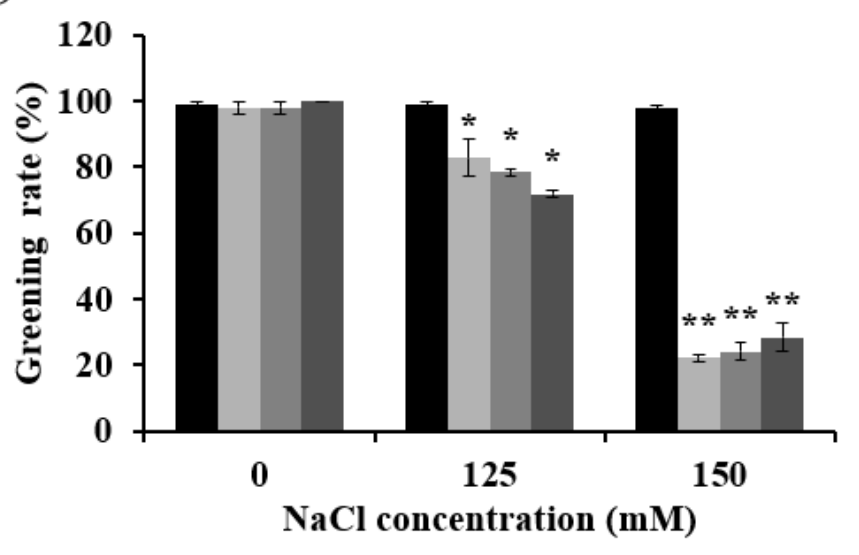

Fig. 5

Figure 5

Germination and greening rates of wild type (WT) and transgenic (TG1, TG3 and TG6) plants in response to salt treatment. A, seed germination of WT and AsHSP26.8a TG plants subjected to 0,125 and $150 \mathrm{mM}$ of $\mathrm{NaCl} 6 \mathrm{~d}$ after treatment. B, germination and C, greening percentages of WT and TG seeds subjected to 0,125 and $150 \mathrm{mM} \mathrm{NaCl} 6 \mathrm{~d}$ after treatment $(\mathrm{n}=3)$. Each column represents mean of three biological replicates. Error bars represent SE. ' $*$ ' or ' $* *$ ' indicate significant differences between TG and WT plants at $\mathrm{P}<0.05$ or 0.01 respectively by Student's $t$ test. The layout of the plates is shown on the upper right-hand corner. 
A

6d
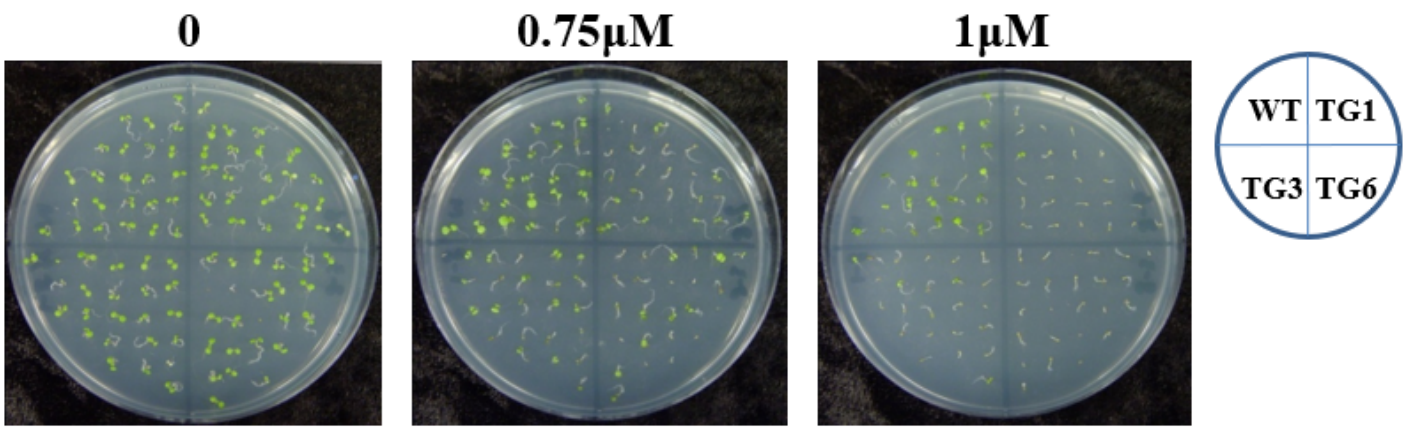

8d
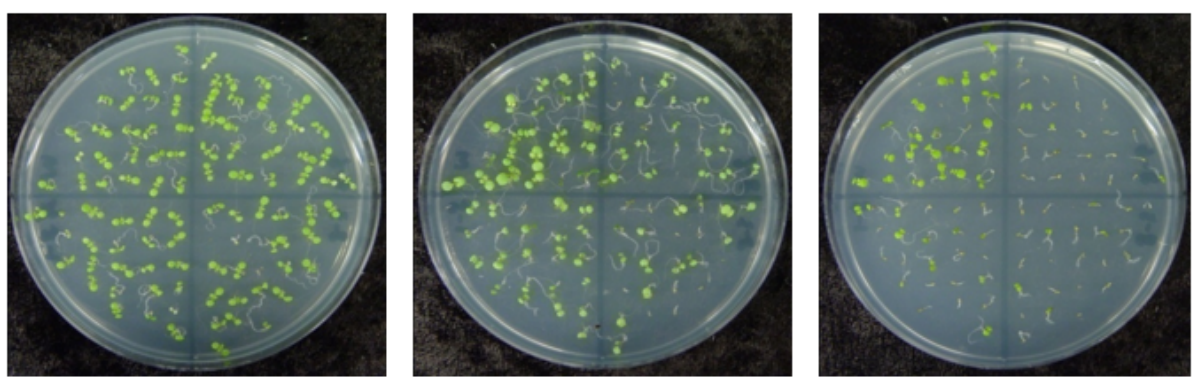

-WT $\backsim$ TG1 $\backsim$ TG3 $\backsim$ TG6
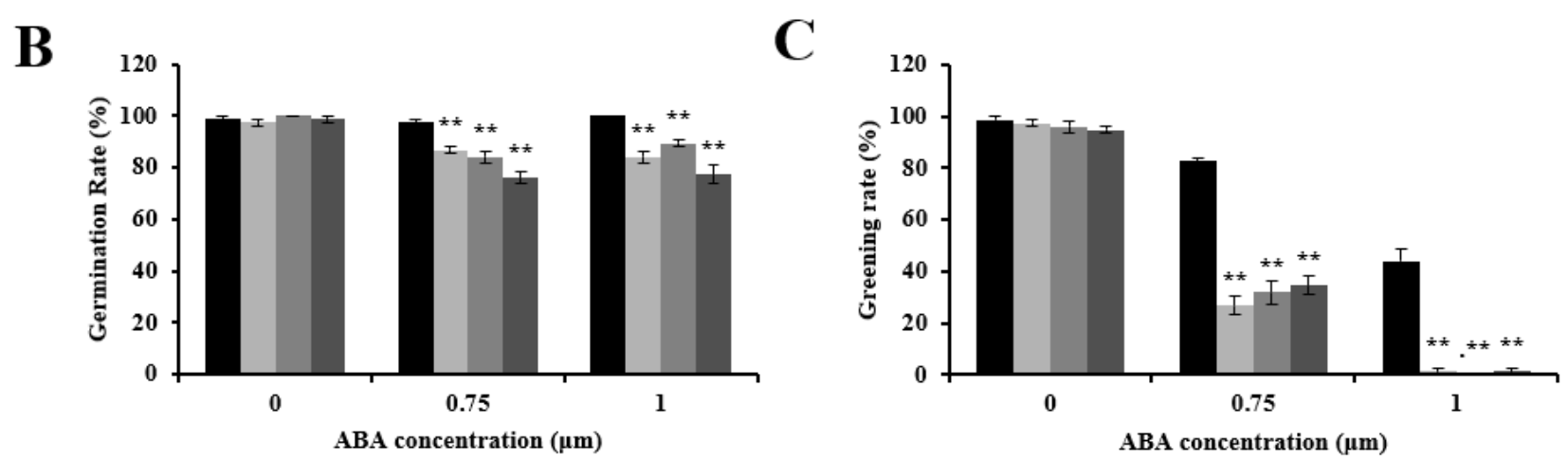

Fig. 6

\section{Figure 6}

Germination and greening rates of wild type (WT) and transgenic (TG1, TG3 and TG6) plants in response to abscisic acid (ABA). A, seed germination of WT and AsHSP26.8a TG plants subjected to 0, 0.75 and 1 $\mu \mathrm{M}$ of $\mathrm{ABA} 6$ and $8 \mathrm{~d}$ after treatment. B, germination percentages of WT and TG seeds subjected to 0 , 0.75 and $1 \mu \mathrm{M}$ of ABA $6 \mathrm{~d}$ after treatment $(n=3)$. C, greening percentages of WT and TG seeds (percentages of seeds with fully expanded cotyledons) subjected to $0,0.75$ and $1 \mu \mathrm{M}$ of ABA $6 \mathrm{~d}$ after treatment $(n=3)$. Each column represents mean of three biological replicates. Error bars represent $S E$. ' $*$ ' or ' $* *$ ' indicate significant differences between TG and WT plants at $\mathrm{P}<0.05$ or 0.01 respectively by Student's $t$ test. The layout of the plates is shown on the upper right-hand corner. 
response to water deprivation systemic acquired resistance, salicylic acid mediated signaling. jasmonic acid mediated signaling pathway abscisic acid-activated signaling pathway response to ethylene response to jasmonic acid ethylene-activated signaling pathway ethylene biosynthetic process response to abscisic acid response to cold response to auxin response to salt stress

MAPK cascade

hyperosmotic salinity response regulation of hydrogen peroxide metabolic process response to oxidative stres jasmonic acid biosynthetic process response to salicylic acid salicylic acid biosynthetic proces response to cadmium ion response to nitrate salicylic acid mediated signaling pathway signal transduction response to hea response to gibberellin heat acclimation proline transport

response to hydrogen peroxide polyamine catabolic process cellular response to stress response to brassinosteroid jasmonic acid and ethylene-dependent systemic resistance response to abiotic stimulus response to stress response to hormone cellular response to heat

$$
0
$$

Fig. 7

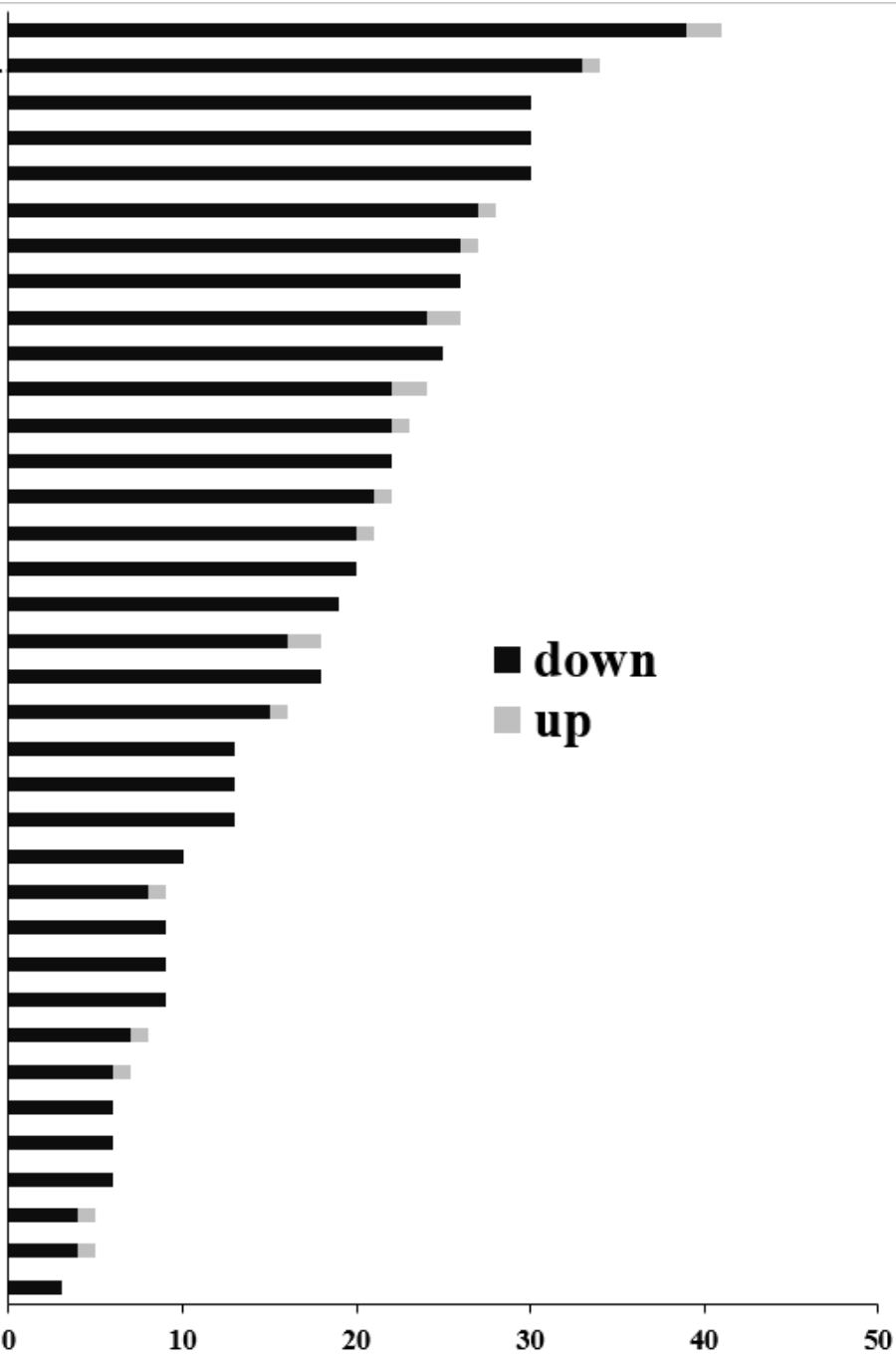

Gene number

\section{Figure 7}

Gene ontology (GO) classification for abiotic stress-related differentially expressed genes (DEGs) in wild type (WT) and AsHSP26.8a transgenic (TG) plants. The y-axis and $x$-axis indicate the names of clusters and the gene number of each cluster, respectively. Only the biological processes were used for GO term analysis.

\section{Supplementary Files}

This is a list of supplementary files associated with this preprint. Click to download.

- 030920Supplementalfigures.pptx

- 030920SupplementalTableS2.doc

- 030920SupplementalTableS1.xlsx

- 0312200rinigalgelimages.pptx 